Review

\title{
A Review on Visible Light Active Perovskite-Based Photocatalysts
}

\section{Pushkar Kanhere ${ }^{1,2, *}$ and Zhong Chen ${ }^{1,2, *}$}

1 Energy Research Institute @ NTU, 1 CleanTech Loop, Clean Tech One, Singapore 637141, Singapore

2 School of Materials Science and Engineering, Nanyang Technological University, 50 Nanyang Avenue, Singapore 639798, Singapore

* Authors to whom correspondence should be addressed; E-Mails: pkanhere@gmail.com (P.K.); ASZChen@ntu.edu.sg (Z.C.); Tel.: +65-67904256 (Z.C.); Fax: +65-67909081 (Z.C.).

External Editor: Pierre Pichat

Received: 25 September 2014; in revised form: 13 November 2014 / Accepted: 16 November 2014 / Published: 1 December 2014

\begin{abstract}
Perovskite-based photocatalysts are of significant interest in the field of photocatalysis. To date, several perovskite material systems have been developed and their applications in visible light photocatalysis studied. This article provides a review of the visible light $(\lambda>400 \mathrm{~nm})$ active perovskite-based photocatalyst systems. The materials systems are classified by the B site cations and their crystal structure, optical properties, electronic structure, and photocatalytic performance are reviewed in detail. Titanates, tantalates, niobates, vanadates, and ferrites form important photocatalysts which show promise in visible light-driven photoreactions. Along with simple perovskite $\left(\mathrm{ABO}_{3}\right)$ structures, development of double/complex perovskites that are active under visible light is also reviewed. Various strategies employed for enhancing the photocatalytic performance have been discussed, emphasizing the specific advantages and challenges offered by perovskite-based photocatalysts. This review provides a broad overview of the perovskite photocatalysts, summarizing the current state of the work and offering useful insights for their future development.
\end{abstract}

Keywords: perovskite; photocatalysis; visible light active; water splitting; doping 


\section{Introduction}

Photocatalysis has long been studied for clean energy and environmental applications. Over the past two decades, the number of applications based on photocatalysis has increased sharply, while a wide range of materials systems have been developed [1-4]. Photocatalysis has been of particular interest in the production of hydrogen from water using solar energy [5]. Further, conversion of $\mathrm{CO}_{2}$ to hydrocarbons (fuels) is also of significant interest, as it is a solution to reduce $\mathrm{CO}_{2}$ emissions across the globe [6,7]. Apart from the clean energy generation, photocatalysis has several promising applications in the environmental field. Some of the applications include degradation of volatile organic compounds (VOC) for water treatment [8], germicide and antimicrobial action [9-11], de-coloration of industrial dyes [12-14], nitrogen fixation in agriculture [15], and removal of $\mathrm{NO}_{\mathrm{x}} / \mathrm{SO}_{\mathrm{x}}$ air pollutants [16-19]. These applications have driven the development of variety of materials systems which are suitable for specific applications. Although $\mathrm{TiO}_{2}$-based materials are the most studied for photocatalytic applications, ternary and other complex oxide systems have been increasingly explored as photocatalysts. Among the various classes of materials studied, perovskites-based photocatalysts have unique photophysical properties and offer distinct advantages.

Perovskites are the class of compounds presenting the general formula $\mathrm{ABO}_{3}$. Generally, in this crystal structure, the A site is occupied by the larger cation, while the B site is occupied by the smaller cation. Perovskites are one of the most important families of materials exhibiting properties suitable for numerous technological applications [20]. Perovskite compounds such as $\mathrm{PbZrO}_{3}, \mathrm{BaTiO}_{3}, \mathrm{PbTiO}_{3}$ are most commonly used piezoelectric compounds [21]. $\mathrm{BiFeO}_{3}$ thin films show multiferroic behavior [22], while compounds such as $\mathrm{SrTiO}_{3}$ have shown excellent photocatalytic properties $[23,24]$. The origin of such properties lies in the crystal structure of perovskites. The perovskite crystal structure has corner connected $\mathrm{BO}_{6}$ octahedra and 12 oxygen coordinated $\mathrm{A}$ cations, located in between the eight $\mathrm{BO}_{6}$ octahedra (Figure 1). The perfect structure of the octahedral connection results in a cubic lattice. However, depending on the ionic radii and electronegativity of the A and B site cations, tilting of the octahedra takes place, which gives rise to lower symmetry structures. As seen from the crystal structure, B site cations are strongly bonded with the oxygen (or any other anion) while, A site cations have relatively weaker interactions with oxygen. Depending on the type of the cations occupying the lattice sites, these interactions could be altered to yield the different perovskite crystal geometries.

Figure 1. Crystal structure of simple Perovskite, (a) $\mathrm{BaTiO}_{3}$ and (b) double perovskite $\mathrm{Na}_{2} \mathrm{Ta}_{2} \mathrm{O}_{6}$ (red: oxygen, green and purple: A site cation, grey and blue: $\mathrm{BO}_{6}$ octahedra).

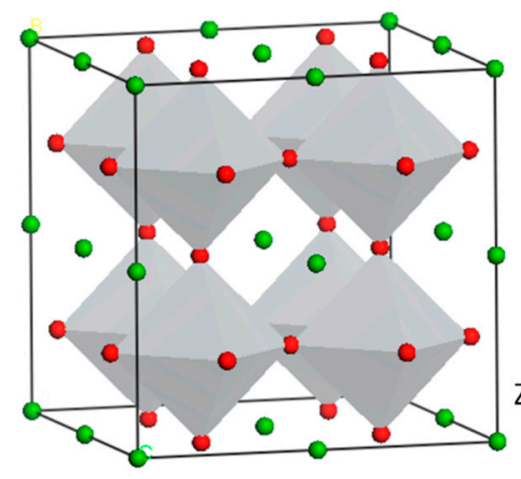

(a)
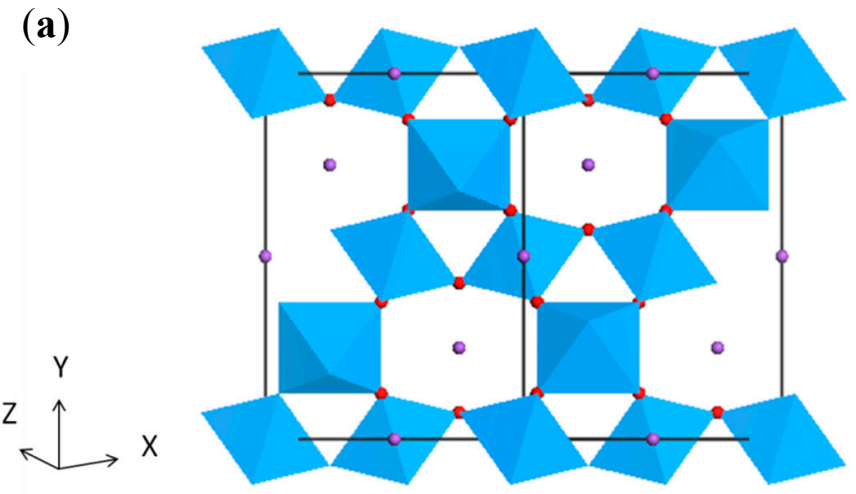

(b)

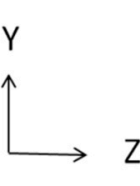


For example, different degrees of tilting of the octahedra give rise to different crystal fields, which result in different electronic and optical properties. The degrees of tilting may affect the band structure, electron and hole transport properties, photoluminescence, and dielectric behavior [25,26]. From the point of view of photocatalysis, perovskite structures may offer significant advantages over the corresponding binary oxides for several reasons. Firstly, perovskites could offer favorable band edge potentials which allow various photoinduced reactions. For example, as compared to the binary oxides, several perovskites have sufficiently cathodic conduction band (CB) energies for hydrogen evolution. Secondly, A and B site cations in the lattice give a broader scope to design and alter the band structure as well as other photophysical properties. In the case of double perovskites such as $\mathrm{A}_{2} \mathrm{~B}_{2} \mathrm{O}_{6}$, stoichiometric occupation of two cations at the B site is known to be beneficial for visible light photocatalysis. Thirdly, some studies have shown that it is possible to combine the effects such as ferroelectricity or piezoelectricity with the photocatalytic effect to benefit the photocatalytic activity.

Perovskite photocatalysts have been studied to a great extent because of their promise for being visible light active. A review of the present work on the visible light driven perovskite photocatalyts is essential to provide a broad overview and possible future directions. Shi et al. reported a general review of perovskite photocatalysts active under UV and visible light [27]. The current review article is focused on visible light active perovskite compounds. We emphasize the strategies used to develop or enhance the visible light absorption and subsequent photocatalytic activities. Further, we attempt to shed some light on the underlying principles specific to the perovskite crystal structure which play an important role in the photocatalytic activity, suggesting potential areas in the field where further work is needed. The first section of the article discusses the mechanism and thermodynamics of some of the most important photocatalytic reactions, while the later section reviews the material systems in detail. In the current review, perovskites are broadly divided into simple $\left(\mathrm{ABO}_{3}\right.$ type) perovskites and complex perovskites (double, layered, etc.).

\section{Overview of Photocatalytic Reactions}

Photocatalysis is a process that utilizes the energy input from incident radiation and the catalytic properties of the surface of a material to carry out and/or accelerate certain chemical reactions. To date, numerous chemical reactions have been studied, which are potentially useful in energy generation and environmental cleaning applications. Photocatalysis is known to be able to produce thermodynamically uphill reactions, which otherwise need intense energy inputs in terms of high temperature (or pressure). Understanding the mechanism of photocatalytic reactions is critically important to design and develop new photocatalytic materials. In this section, a brief review of mechanism and thermodynamics of most common photocatalytic reactions is presented. Figure 2 shows the reduction and oxidation levels of some of the common photocatalytic reactions with reference to vacuum and the normal hydrogen electrode (NHE). It is noted that these values provide an insight only on the thermodynamic feasibility of the reaction. It is seen that for the reduction reaction, the energy of the (photoexcited) electron should be higher (on the absolute vacuum scale) than the redox level. Therefore the $\mathrm{CB}$ potential of the photocatalyst should be located at a higher energy value than the reduction reaction of interest. 
Figure 2. Energy levels of some of the important photocatalytic reactions with respect to $\mathrm{NHE}$ at $\mathrm{pH}=0$ [28].

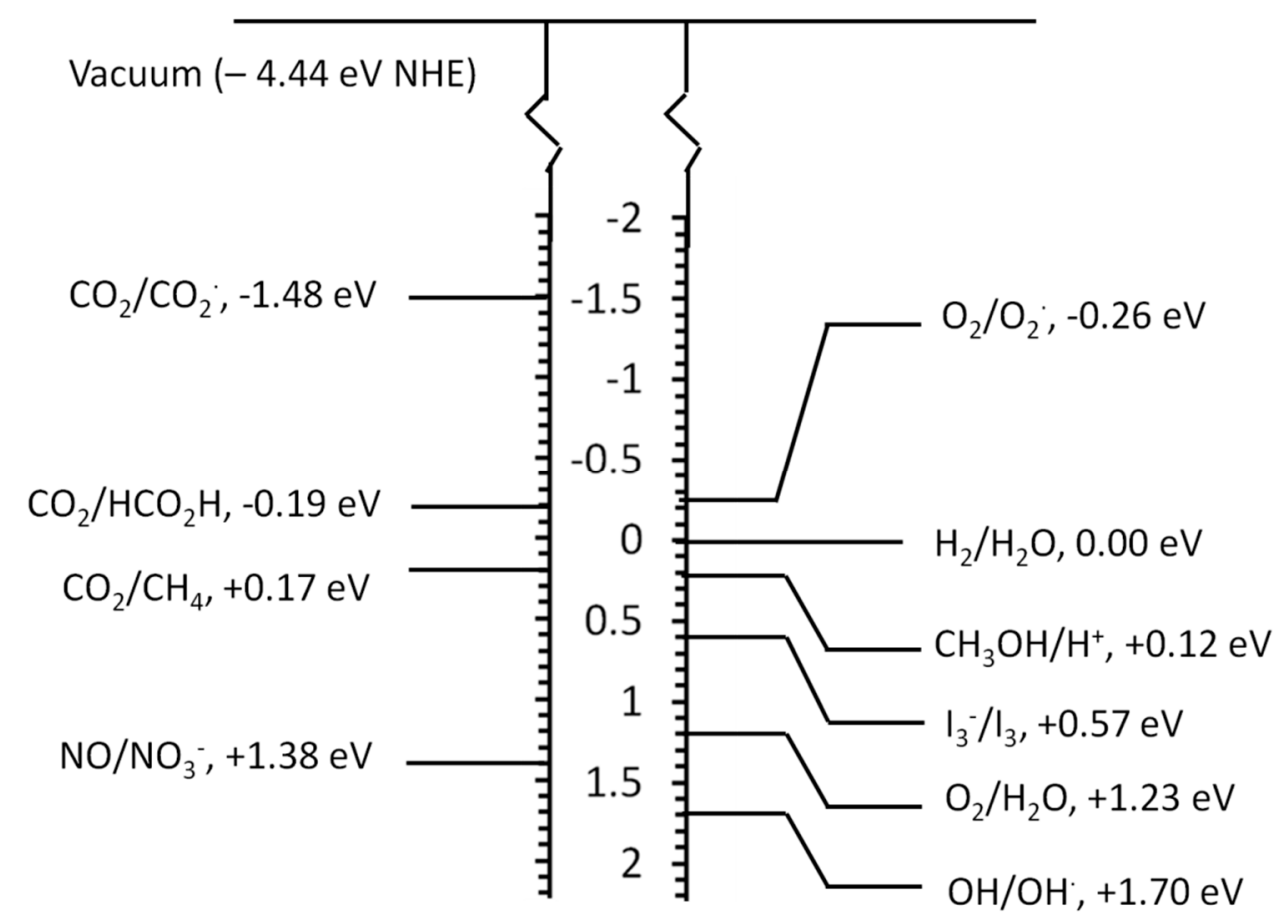

\subsection{Photocatalytic Water Splitting}

One of the most studied reactions is the direct splitting of water into hydrogen and oxygen. Figure 3 shows the schematics of the water splitting reaction according to the 4-photon model [29].

Figure 3. Band diagram and schematics of water splitting reaction over a photocatalyst surface [30].

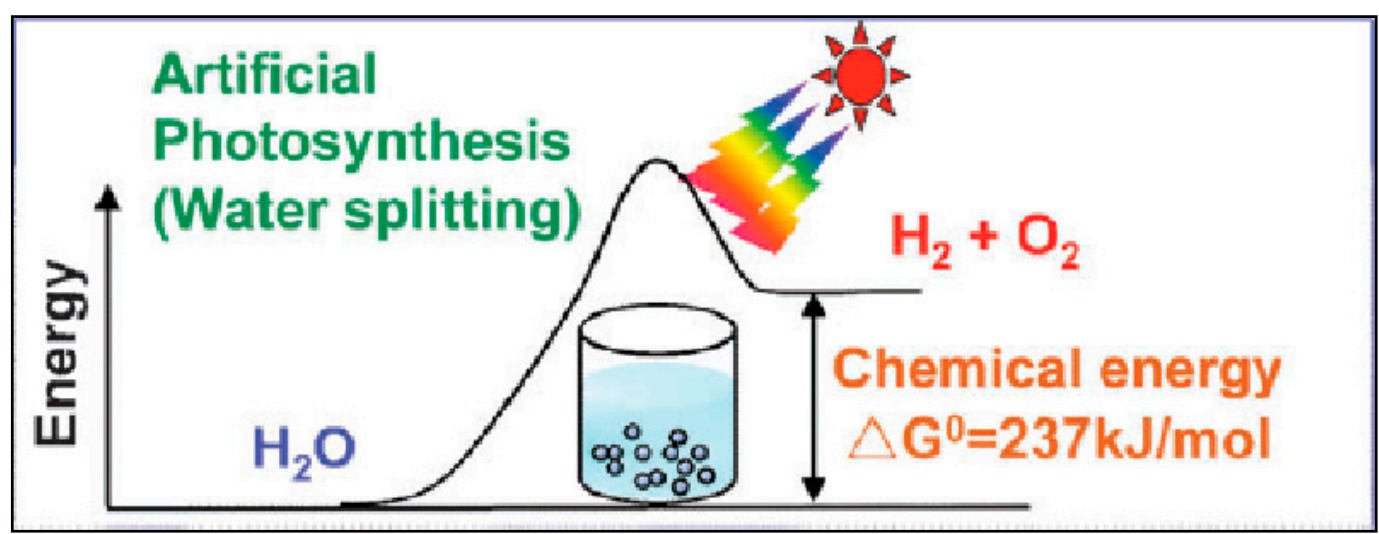

In the water splitting reaction, upon the radiation of photon with suitable wavelength, photoexcited pairs of electrons and holes are generated within a photocatalyst. Typically, electron-hole separation takes place, due to surface charge or co-catalyst loading. Direct oxidation of water molecules, chemisorbed on the surface of the photocatalyst (or co-catalyst) occurs, by the interaction of water molecule and hole in the valence band (VB) of the photocatalyst. This reaction results in liberation of 
an oxygen molecule and 4-protons. The protons then migrate to the sites of photoexcited electrons to form hydrogen molecules (Equations (1)-(3)).

$$
\begin{gathered}
2 \mathrm{H}_{2} \mathrm{O} \rightarrow 2 \mathrm{H}_{2}+\mathrm{O}_{2} \Delta \mathrm{H}=+234 \mathrm{~kJ} / \mathrm{mol} \\
2 \mathrm{H}_{2} \mathrm{O} \rightarrow 4 \mathrm{H}^{+}+\mathrm{O}_{2} \\
4 \mathrm{H}^{+}+4 \mathrm{e}^{-} \rightarrow 2 \mathrm{H}_{2}
\end{gathered}
$$

Evolution of hydrogen and oxygen using sunlight is considered as one of the most promising ways to generate hydrogen as a clean and renewable fuel. Like the water molecule, other molecules also undergo decomposition by the process of photocatalysis.

\subsection{Photooxidation of Organic Molecules}

Several organic compounds undergo photooxidation reactions, where a direct oxidation via photogenerated holes occurs or an indirect oxidation via hydroxyl ions takes place [31]. The degradation of organic molecules also takes place by reactive oxygen species (Figure 4). Organic dyes, aliphatics and aromatic hydrocarbons, and organic acids can be mineralized to $\mathrm{CO}_{2}$ and $\mathrm{H}_{2} \mathrm{O}$ by photocatalytic processes. Like organic compounds, hydroxyl ions and reactive oxygen species (ROS) are known to inactivate microorganisms by degrading their cell walls [10,32]. The photocatalytic inactivation of microbes is effective in antimicrobial, antifungal and antiviral applications. A later section reviews certain silver- and bismuth-based perovskites which display particularly efficient antimicrobial action under visible light.

Figure 4. Band diagram and schematics of degradation of organic compounds over a photocatalyst surface $[12,33]$.

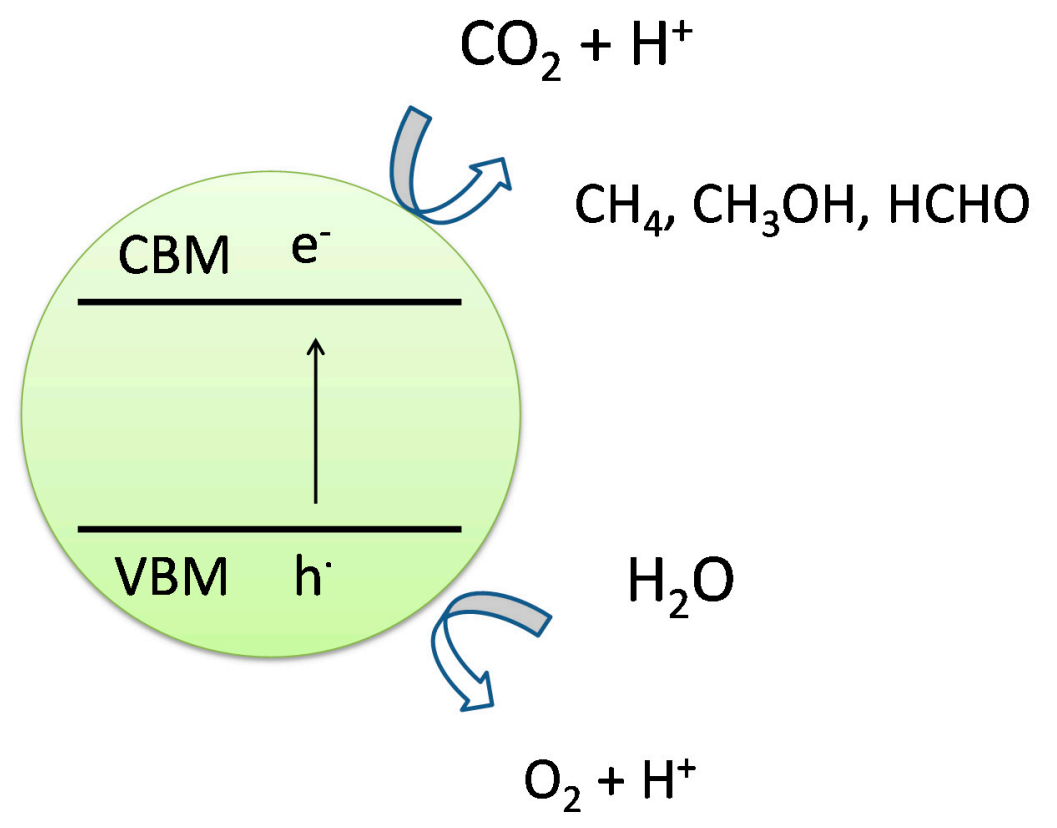




\subsection{Photocatalytic Conversion of $\mathrm{CO}_{2}$ to Fuels}

$\mathrm{CO}_{2}$, with a standard enthalpy of formation of $-393.5 \mathrm{~kJ} \cdot \mathrm{mol}^{-1}$ at $298 \mathrm{~K}$, is one of the most stable molecules. With appropriate adsorption and photocatalytic processes, reduction of $\mathrm{CO}_{2}$ in presence of water could be performed to produce hydrocarbons (Figure 5). Possible chemical reactions of adsorbed $\mathrm{CO}_{2}$ and protons are presented by the following equations (Equations (4)-(7)). It could be seen that different number of protons in the reactants, results in different hydrocarbons as products.

Figure 5. Schematics of $\mathrm{CO}_{2}$ photoreduction reaction over a photocatalyst surface [34].

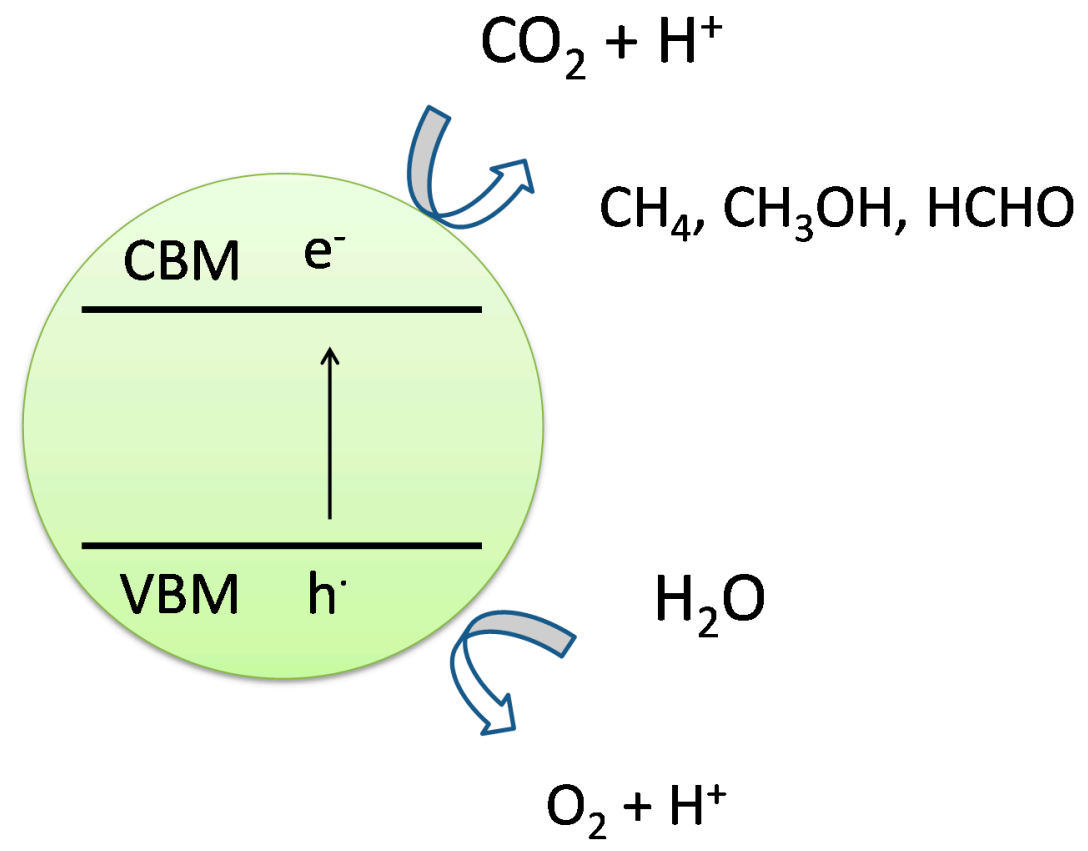

Among these reactions, the reaction with eight protons converting $\mathrm{CO}_{2}$ to methane is of significant interest. The photocatalytic reduction of $\mathrm{CO}_{2}$ in the presence of water is a complex reaction and the photocatalyst must possess enough band potential for proton generation:

$$
\begin{gathered}
\mathrm{CO}_{2}+2 \mathrm{H}^{+}+2 \mathrm{e}^{-} \rightarrow \mathrm{CO}+\mathrm{H}_{2} \mathrm{O} \\
\mathrm{CO}_{2}+6 \mathrm{H}^{+}+6 \mathrm{e}^{-} \rightarrow \mathrm{CH}_{3} \mathrm{OH}+\mathrm{H}_{2} \mathrm{O} \\
\mathrm{CO}_{2}+8 \mathrm{H}^{+}+8 \mathrm{e}^{-} \rightarrow \mathrm{CH}_{4}+\mathrm{H}_{2} \mathrm{O} \\
2 \mathrm{CO}_{2}+12 \mathrm{H}^{+}+12 \mathrm{e}^{-} \rightarrow \mathrm{C}_{2} \mathrm{H}_{5} \mathrm{OH}+\mathrm{H}_{2} \mathrm{O}
\end{gathered}
$$

\subsection{Photocatalytic Nitrogen Fixation}

Like $\mathrm{CO}_{2}$ reduction, atmospheric nitrogen could be reduced to ammonia or nitrates by the photocatalytic processes. The mechanism of nitrogen reduction is similar to that of $\mathrm{CO}_{2}$, where chemically adsorbed nitrogen molecules react catalytically with protons and form compounds of nitrogen and hydrogen (Equations (8)-(10)):

$$
\begin{gathered}
\mathrm{H}_{2} \mathrm{O}\left(\mathrm{hv} / \mathrm{TiO}_{2}\right) \rightarrow 2 \mathrm{H}^{+}+{ }_{1 / 2} \mathrm{O}_{2}+2 \mathrm{e}^{-} \\
\mathrm{H}^{+}+\mathrm{e}^{-} \rightarrow \mathrm{H}
\end{gathered}
$$




$$
\mathrm{N}_{2}+\mathrm{H} \cdot \rightarrow \mathrm{N}_{2} \mathrm{H}
$$

The photocatalytic reduction of nitrogen is extremely useful in nitrogen photofixation processes for agricultural applications [35-37]. Although the process of photocatalytic nitrogen fixation is promising, efforts in this area have been severely limited. It is noted that the mechanism of the photocatalytic processes presented above is a simplified understanding, while the photocatalytic processes are complex in nature.

It is known that a given chemical reaction has a specific photooxidation or photoreduction level (potential) and thus the band potentials of the photocatalyst must satisfy the thermodynamic conditions. Intrinsic properties such as band gap (optical absorption) and band edge potentials determine the thermodynamic feasibility of photoinduced reactions under light irradiation. Apart from the basic conditions, there are several factors which affect the photocatalytic performance of the material system under consideration. Properties such as electron and hole effective mass, exciton lifetime and diffusion length, exciton binding energy affect the electron-hole separation and transport within the lattice. These properties are known to strongly influence the performance (kinetics/efficiency) of the photocatalytic reactions. Defects in the lattice, defect-induced energy states, localization of electrons on specific defect sites could determine the fate of the photoexited electron-hole pair. Finally, the electron transfer across semiconductor-electrolyte interface is significantly affected by surface states, surface band structure (depletion region induced electric field), and band bending. Such electronic properties of materials could be altered to suit specific photocatalytic applications. To date, numerous material systems have been evolved through systematic efforts of understanding and improving the electronic properties of materials. Among these materials perovskites have shown excellent promise for efficient photocatalysis under visible light irradiation, on account of their unique crystal structure and electronic properties. The perovskite crystal structure offers an excellent framework to tune the band gap values to enable visible light absorption and band edge potentials to suit the needs of specific photocatalytic reactions. Further, lattice distortion in perovskite compounds strongly influences the separation of photogenerated charge carriers. The following sections present some groups of materials that have shown visible light activity.

\section{Simple Perovskites with Visible Light Response}

\subsection{Titanate Perovskites}

Titanate perovskites have been studied for photocatalytic applications for a long time. Most of the titanate perovskites have band gap energy $\left(\mathrm{E}_{\mathrm{g}}\right)$ value more than $3.0 \mathrm{eV}$, however they show excellent photocatalytic properties under UV radiation [1]. Using these titanates as host materials, doping is widely used to alter the optical properties and induce visible light absorption. $\mathrm{TiO}_{2}$ (anatase) has a band gap of 3.2-3.4 eV and its $\mathrm{CB}$ potential is -0.3 to $-0.6 \mathrm{eV}$ above the water reduction level [38]. Certain perovskite titanates have $\mathrm{CB}$ energies more negative than $\mathrm{TiO}_{2}$, making them more suitable candidates for hydrogen generation. Titanates also offer good photostability and corrosion resistance in aqueous solutions. In this section, a detailed review of $\mathrm{MTiO}_{3}(\mathrm{M}=\mathrm{Sr}, \mathrm{Ba}, \mathrm{Ca}, \mathrm{Mn}, \mathrm{Co}, \mathrm{Fe}, \mathrm{Pb}, \mathrm{Cd}, \mathrm{Ni})$ systems is presented. Figure 6 gives an overview of elements that form perovskite titanates. 
Figure 6. Overview of elements forming perovskite titanates useful for visible light photocatalysis.
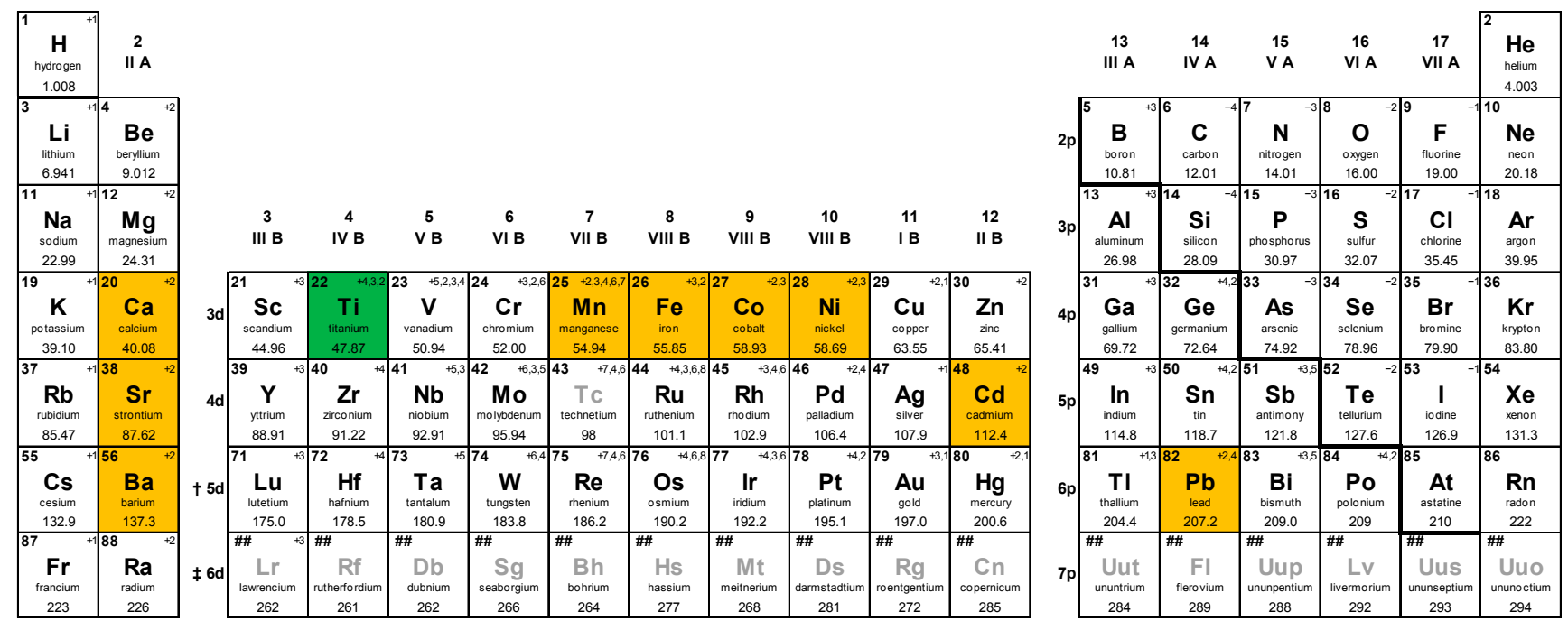

\subsection{1. $\mathrm{SrTiO}_{3}$}

$\mathrm{SrTiO}_{3}$ is a simple cubic ( $\mathrm{Pm} 3 \mathrm{~m}, \mathrm{a}=3.9 \AA$ ) perovskite with an indirect band gap of $3.25 \mathrm{eV}$ [39]. When loaded with a co-catalyst such as $\mathrm{Rh}$ or $\mathrm{NiO}_{x}, \mathrm{SrTiO}_{3}$ shows stoichiometric water splitting under UV radiation [40] and has been studied extensively for developing visible light water splitting catalysts. Doping of the Ti site with $\mathrm{Mn}, \mathrm{Ru}, \mathrm{Rh}$, and Ir was of significant interest in early days [41]. It is found that these dopants induce mid-gap states in the band gap allowing visible light absorption [42]. Mn and $\mathrm{Ru}$ doping are found useful for $\mathrm{O}_{2}$ evolution, while dopants like $\mathrm{Ru}, \mathrm{Rh}$, and $\mathrm{Ir}$ are suitable for $\mathrm{H}_{2}$ evolution [41]. Rh-doped $\mathrm{SrTiO}_{3}$ thin films also shows cathodic photocurrent from overall water splitting under visible light, where 7\% $\mathrm{Rh}$ doped $\mathrm{SrTiO}_{3}$ showed $0.18 \%$ incident photo-to-electron conversion efficiency (IPEC) under $420 \mathrm{~nm}$ irradiation [43]. Using Rh-doped $\mathrm{SrTiO}_{3}$ as a $\mathrm{H}_{2}$ evolving photocatalyst, various $\mathrm{Z}$ scheme systems have been developed. In a significant demonstration, a novel electron mediator $[\mathrm{Co}(\text { bpy }) 3]^{3+/ 2+}$ was used for $\mathrm{Rh}$-doped $\mathrm{SrTiO}_{3}$ with $\mathrm{BiVO}_{4}$ photocatalyst. Such a system showed a solar energy conversion efficiency of $0.06 \%$ under daylight [44]. Efforts in $\mathrm{Z}$ scheme photocatalysis have also been targeted towards eliminating the need for electron mediators by preparing composite photocatalysts. In such systems, electrons from an $\mathrm{O}_{2}$ evolving photocatalyst recombine with holes from a $\mathrm{H}_{2}$ evolving photocatalyst at the interface of the composite. The quality of the interface and the band alignment of the two semiconductors are important factors for the successful realization of mediator-free type $\mathrm{Z}$ schemes.

Rh-doped $\mathrm{SrTiO}_{3}$ was combined with several $\mathrm{O}_{2}$-evolving photocatalysts such as $\mathrm{BiVO}_{4}, \mathrm{AgNbO}_{3}$, $\mathrm{Bi}_{2} \mathrm{MoO}_{6}, \mathrm{WO}_{3}$, or $\mathrm{Cr} / \mathrm{Sb}$-doped $\mathrm{TiO}_{2}$ [45]. In those experiments the authors found that agglomeration of the photocatalyst particles occur under acidic conditions, which results in $\mathrm{Z}$ scheme photocatalysis. A combination of $\mathrm{Rh}$-doped $\mathrm{SrTiO}_{3}$ and $\mathrm{BiVO}_{4}$ resulted in the best yield [45]. A schematic of microstructure and mechanism of water splitting of an agglomerated $\mathrm{Z}$ scheme photocatalyst is shown in Figure 7. In a recent effort, a composite of $1 \% \mathrm{Rh}$-doped $\mathrm{SrTiO}_{3}$ loaded with $0.7 \% \mathrm{Ru}$ and $\mathrm{BiVO}_{4}$ was successfully prepared. Such a composite showed a stoichiometric water splitting reaction (pH 7) 
with quantum yield (QY) of 1.6\% at $420 \mathrm{~nm}$ [23]. These studies successfully establish the feasibility of the " $\mathrm{Z}$ scheme" photocatalysis for candidates such as $\mathrm{Rh}$-doped $\mathrm{SrTiO}_{3}$ under visible light.

Figure 7. (a) Schematic microstructure and (b) band diagram of $Z$ scheme photocatalysis using Rh-doped $\mathrm{SrTiO}_{3}$ [45].

(a)

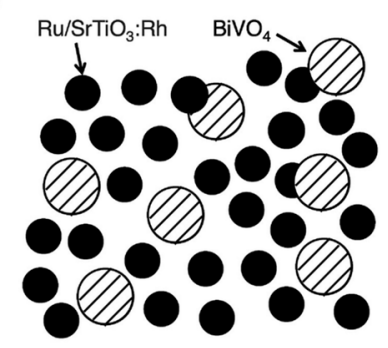

Neutral pH conditions

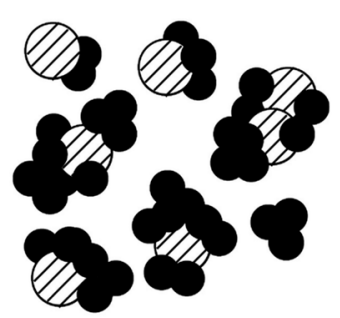

Acidic conditions

(b)

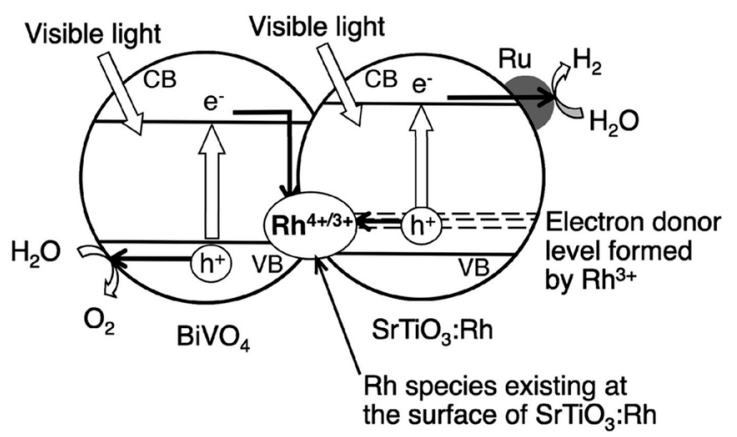

Further, the water splitting efficiency is dependent on the synthesis method used for Rh-doped $\mathrm{SrTiO}_{3}$ [46]. The use of excess $\mathrm{Sr}$ in hydrothermal and complex polymerization methods proved useful for improving the apparent yield to $4.2 \%$ under $420 \mathrm{~nm}$ radiation [46]. Apart from mono-doping, co-doping has been employed in $\mathrm{SrTiO}_{3}$ to pursue visible light driven photocatalysis. Co-doping of $\mathrm{Sb}$ (1\%) and $\mathrm{Rh}(0.5 \%)$ was found useful for visible light photocatalysis and estimated $\mathrm{H}_{2}$ and $\mathrm{O}_{2}$ evolution rates for $1 \mathrm{~m}^{2}$ surface area were $26 \mathrm{~mL} \cdot \mathrm{h}^{-1}$ and $13 \mathrm{~mL} \cdot \mathrm{h}^{-1}$, respectively [47]. Further, a composite system was prepared from co-doped $\mathrm{La}-\mathrm{Cr}$ in $\mathrm{SrTiO}_{3}$ and co-doped $\mathrm{La}-\mathrm{Cr} \mathrm{Sr}_{2} \mathrm{TiO}_{4}$ which showed visible light driven $\mathrm{H}_{2}$ evolution $\left(24 \mu \mathrm{mol} \cdot \mathrm{h}^{-1} \cdot \mathrm{g}^{-1}\right)$ [48]. Composite preparation led to heterojunctions between doped phases and produced a synergistic effect for hydrogen evolution. Further, a solid solution of $\mathrm{AgNbO}_{3}$ and $\mathrm{SrTiO}_{3}$ was discovered to be a visible light active photocatalyst [49]. $\left(\mathrm{AgNbO}_{3}\right)_{0.75}\left(\mathrm{SrTiO}_{3}\right)_{0.25}$ showed promising performance for $\mathrm{O}_{2}$ evolution and isopropanol (IPA) degradation under visible light.

Several efforts have been made to understand and design $\mathrm{SrTiO}_{3}$-based photocatalysts. Particularly DFT-based band structure calculations provide useful insights into the electronic structure and its correlation with photocatalytic activity. It is shown that $\mathrm{Rh}$ doping in $\mathrm{SrTiO}_{3}$ produces band-like states above the valence band maximum (VBM) which are responsible for the visible light absorption. The proximity of dopant-induced states to VBM helps efficient replenishment of electrons and suppresses electron trapping from $\mathrm{CB}$ [42]. Theoretical calculations indicate that a $\mathrm{TiO}_{2}$-terminated $\mathrm{SrTiO}_{3}$ surface with defects such as $\mathrm{O}$ and $\mathrm{Sr}$ vacancies would alter its electronic structure and induce visible light absorption peaking around $420 \mathrm{~nm}$ [50]. Such strategies could be useful in the development of low dimensional materials. Further, theoretical work on doped $\mathrm{SrTiO}_{3}$ compounds show that certain 
dopants such as La strongly lower the effective mass of electrons and holes (near the valence band region), increasing the mobility of the photoexited carrier [51]. Along with the ground state band structure calculations, study of electron and hole masses, defect chemistry, photoexcited transport could be carried out to understand this system in detail. Understanding the excited state properties is useful in further development of new photocatalysts.

\subsection{2. $\mathrm{BaTiO}_{3}$}

Like $\mathrm{SrTiO}_{3}$, Rh doping in $\mathrm{BaTiO}_{3}$ has been carried out and a quantum yield of $0.5 \%$ under $420 \mathrm{~nm}$ was reported [52]. Being a hydrogen evolving catalyst, this material has also been used as $\mathrm{Z}$ scheme with $\mathrm{Pt} / \mathrm{WO}_{3}$ for overall water splitting [52].

\subsection{3. $\mathrm{CaTiO}_{3}$}

Calcium titanate is one of the common perovskite minerals with a band gap of $3.6 \mathrm{eV}$. Cu doping in $\mathrm{CaTiO}_{3}$ is widely studied and visible light-driven photocatalytic water decomposition has been reported [53]. $\mathrm{Cu}$ doping not only induces visible light absorption, but also enhances hydrogen evolution under UV radiation when $\mathrm{NiO}_{x}$ co-catalyst is used. Studies of such doped systems, where dopants enhance the photocatalytic activity host materials are important to design efficient photocatalysts. Detrimental effects of doping on the properties such as electron-hole recombination, electron/hole effective mass, and reduced crystallinity should be studied and reported in detail. These studies are useful to gain insights on the photocatalytic activities of the doped systems. Co-doping of $\mathrm{Ag}$ and $\mathrm{La}$ at $\mathrm{CaTiO}_{3}$ has been done to narrow the band gap and induce visible light absorption [54]. DFT studies also indicate that like $\mathrm{SrTiO}_{3}, \mathrm{TiO}_{2}$-terminated $\mathrm{CaTiO}_{3}$ surfaces possess the capability of visible light absorption [55]. Along with alkali titanates, several transition metal titanates show promise for visible light photocatalysis. Figure 8 shows the empirically estimated band diagram of the $\mathrm{MTiO}_{3}$ systems with respect to water oxidation and reduction levels.

Figure 8. Band edge potentials ( $v s . \mathrm{NHE} ; \mathrm{pH}=0)$ of $\mathrm{MTiO}_{3}$ system [56].

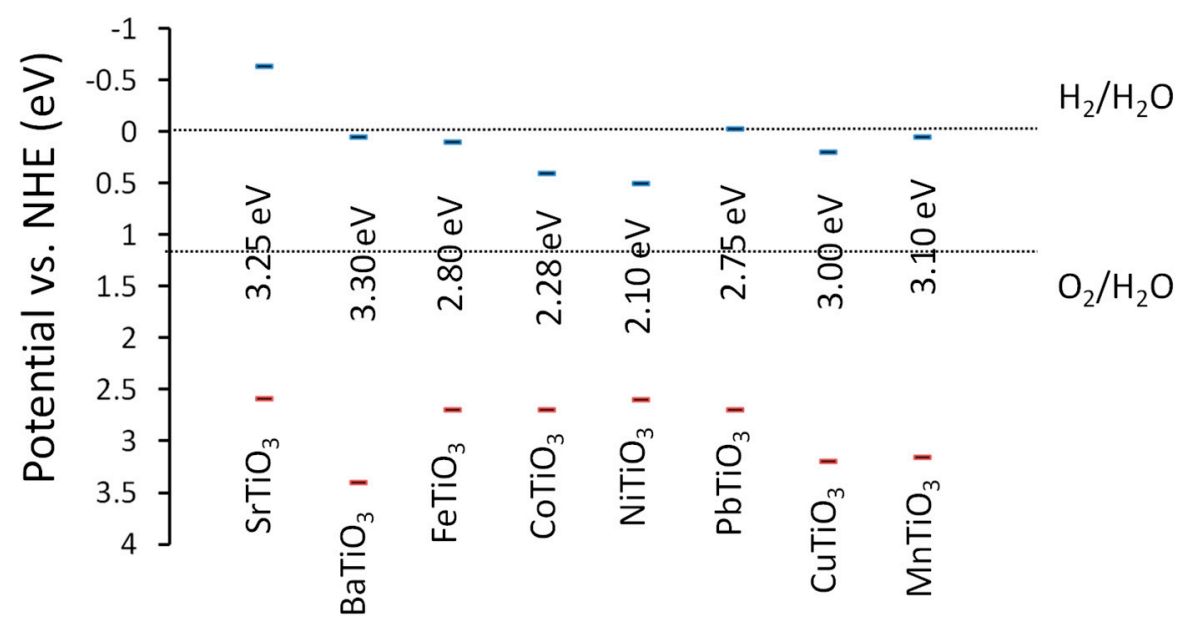

Alkali metal titanates such as $\mathrm{Ba}, \mathrm{Ca}$, and $\mathrm{Sr}$ have enough $\mathrm{CB}$ potential for hydrogen evolution. However, certain transition metal titanates do not possess the desired CB potential for water reduction, 
though they have band gap values in the visible region (such as $\mathrm{Co}, \mathrm{Ni}, \mathrm{Fe}$ etc.). These materials could be suitable for degradation of organics or other photooxidation reactions.

\subsection{4. $\mathrm{CoTiO}_{3}$}

$\mathrm{CoTiO}_{3}$ has a band gap in the visible region $(\mathrm{Eg} 2.28 \mathrm{eV})$. Recently this compound has been investigated for photocatalytic $\mathrm{O}_{2}$ evolution reaction without any co-catalyst [57]. A yield of $64 \mu \mathrm{mol} \cdot \mathrm{g}^{-1} \cdot \mathrm{h}^{-1}$ was obtained under visible light. $\mathrm{CoTiO}_{3}$ and $\mathrm{TiO}_{2}$ composites have been studied for 2-propanol mineralization, however it is worth noting that the band positions of $\mathrm{CoTiO}_{3}$ are not suitable for transferring photoexcited charges to $\mathrm{TiO}_{2}$, offering no significant advantage [58].

\subsection{5. $\mathrm{NiTiO}_{3}$}

$\mathrm{NiTiO}_{3}$ has a reported band gap of around $2.16 \mathrm{eV}$ and its light absorption spectra show peaks in visible region corresponding to crystal field splitting [59]. $\mathrm{NiTiO}_{3}$ nanorods have been employed for degradation of nitrobenzene under visible light [59].

\subsection{6. $\mathrm{FeTiO}_{3}$}

$\mathrm{FeTiO}_{3}$ has a band gap of $2.8 \mathrm{eV}$ and thus it absorbs visible light. Composites of $\mathrm{FeTiO}_{3}$ and $\mathrm{TiO}_{2}$ are studied for the degradation of 2-propenol under visible light. In such composites, $\mathrm{TiO}_{2}$ acts as hole capturing phase, thereby separating the electron-hole recombination [60].

\subsection{7. $\mathrm{CdTiO}_{3}$}

$\mathrm{CdTiO}_{3}\left(\mathrm{Eg}_{\mathrm{g}} 2.8 \mathrm{eV}\right)$ nanofibers were synthesized and studied for the photodegradation of rhodamine 6G (R6G) dye [61].

\subsection{8. $\mathrm{PbTiO}_{3}$}

$\mathrm{PbTiO}_{3}$ has a band gap of $2.75 \mathrm{eV}$ and has been investigated for visible light photocatalysis. Core-shell particles of nano- $\mathrm{TiO}_{2}$ (shell) and micro- $\mathrm{PbTiO}_{3}$ (core) were studied for effective charge separation and photocatalytic performance [62]. It is worth noting that $\mathrm{PbTiO}_{3}$ is ferroelectric in nature while $\mathrm{TiO}_{2}$ is dielectric. It is shown that the ferroelectric behavior helps electron-hole separation at the interface of two particles.

\subsection{9. $\mathrm{MnTiO}_{3}$}

Further, $\mathrm{F}$ doped $\mathrm{MnTiO}_{3}$ shows improved separation of charges and degrades rhodamine $\mathrm{B}$ under visible light [63]. Some of the promising titanates photocatalysts have been listed in Table 1, as a part of compilation of perovskite systems. 
Table 1. Compilation of promising photocatalytic systems for hydrogen or oxygen evolution under visible light.

\begin{tabular}{|c|c|c|c|c|}
\hline Material System & $\begin{array}{c}\text { Irradiation } \\
(\mathbf{n m})\end{array}$ & Photocatalytic Performance & Experimental Details & Ref. \\
\hline $\begin{array}{c}1 \% \mathrm{Rh} \text { doped } \mathrm{SrTiO}_{3} \\
(0.5 \% \mathrm{Pt})\end{array}$ & $420-800$ & $\begin{array}{c}\mathrm{H}_{2} \text { at } 48.1 \mu \mathrm{mol} \cdot \mathrm{h}^{-1} \text { with } \\
\text { sacrificial agent }\end{array}$ & $\begin{array}{l}20 \% \text { methanol, } 50 \mathrm{mg} \text { in } 50 \mathrm{~mL} \\
\text { of solution }\end{array}$ & {$[64]$} \\
\hline Rh: $\mathrm{SrTiO}_{3}: \mathrm{BiVO}_{4}$ & $>420$ & $\begin{array}{l}\mathrm{Z} \text { scheme Water splitting. } \mathrm{H}_{2} \\
\text { at } 128, \mathrm{O}_{2} \text { at } 61 \mu \mathrm{mol} \cdot \mathrm{h}^{-1}\end{array}$ & $\begin{array}{l}4.2 \% \text { Efficiency, } 50 \mathrm{mg} 120 \mathrm{~mL} \\
\left(\mathrm{FeCl}_{3} \text { shuttle }\right)\end{array}$ & [46] \\
\hline $\begin{array}{c}\text { Cr-Sb co-doped } \mathrm{SrTiO}_{3} \\
(0.3 \% \mathrm{Pt})\end{array}$ & $>420$ & $\begin{array}{c}\mathrm{H}_{2} \text { at } 78, \mathrm{O}_{2} \text { at } 0.9 \mu \mathrm{mol} \cdot \mathrm{h}^{-1} \\
\text { with sacrificial agents }\end{array}$ & $\begin{array}{c}\text { in aqueous methanol and } \mathrm{AgNO}_{3} \\
\text { solution }\end{array}$ & {$[65]$} \\
\hline $\mathrm{MCo}_{1 / 3} \mathrm{Nb}_{2 / 3} \mathrm{O}_{3}(0.2 \% \mathrm{Pt})$ & $>420$ & $\begin{array}{c}\mathrm{H}_{2} \text { at } 1.4 \mu \mathrm{mol} \cdot \mathrm{h}^{-1} \text { with } \\
\text { sacrificial agent }\end{array}$ & $\begin{array}{l}500 \mathrm{mg} \text { catalyst in } 50 \mathrm{~mL} \\
\text { methanol, } 220 \mathrm{~mL} \text { water, }\end{array}$ & {$[66]$} \\
\hline $\mathrm{Sr}_{1-\mathrm{x}} \mathrm{NbO}_{3}(1 \% \mathrm{Pt})$ & $>420$ & $\begin{array}{c}\mathrm{H}_{2} \text { at } 44.8 \mu \mathrm{mol} \cdot \mathrm{h}^{-1} \text { with } \\
\text { sacrificial agent }\end{array}$ & $\begin{array}{c}0.025 \mathrm{M} \text { oxalic acid, } 0.1 \mathrm{~g} \text { catalyst } \\
\text { in } 200 \mathrm{~mL},\end{array}$ & {$[67]$} \\
\hline $\mathrm{AgNbO}_{3}-\mathrm{SrTiO}_{3}$ & $>420$ & $\begin{array}{c}\mathrm{O}_{2} \text { at } 162 \mu \mathrm{mol} \cdot \mathrm{h}^{-1} \text { with } \\
\text { sacrificial agent }\end{array}$ & $\begin{array}{l}0.5 \mathrm{~g} \text { catalyst in } 275 \mathrm{~mL} \mathrm{AgNO}_{3} \\
\text { solution, }\end{array}$ & {$[49]$} \\
\hline $\mathrm{LaFeO}_{3}$ (Pt co-catalyst) & $400-700$ & $\begin{array}{c}\mathrm{H}_{2} \text { at } 3315 \mu \mathrm{mol} \cdot \mathrm{h}^{-1} \text { with } \\
\text { sacrificial agent }\end{array}$ & $\begin{array}{c}\mathrm{H}_{2}=3315, \mu \mathrm{mol} \cdot \mathrm{h}^{-1}, 1 \mathrm{mg} \text { in } 20 \\
\mathrm{~mL} \text { of ethanol }\end{array}$ & [68] \\
\hline $\begin{array}{c}\mathrm{CaTi}_{1}{ }_{\mathrm{x}} \mathrm{Cu}_{\mathrm{x}} \mathrm{O}_{3}(\mathrm{x}=0.02) \\
\mathrm{NiO}_{\mathrm{x}} \text { co-catalyst }\end{array}$ & $>400$ & $\begin{array}{c}\mathrm{H}_{2} \text { at } 22.7 \mu \mathrm{mol} \cdot \mathrm{h}^{-1} \text { with } \\
\text { sacrificial agent }\end{array}$ & $\begin{array}{l}100 \text { mg catalyst in } 420 \mathrm{~mL} \\
\text { methanol solution }\end{array}$ & {$[53]$} \\
\hline $\mathrm{PrFeO}_{3},(\mathrm{Pt}$ co-catalyst $)$ & $\begin{array}{l}\text { 200W Tungsten } \\
\text { source }\end{array}$ & $\begin{array}{c}\mathrm{H}_{2} \text { at } 2847 \mu \mathrm{mol} \cdot \mathrm{h}^{-1} \text { with } \\
\text { sacrificial agent }\end{array}$ & $1 \mathrm{mg}$ in $20 \mathrm{~mL}$ ethanol solution & [69] \\
\hline Bi doped $\mathrm{NaTaO}_{3}$ & $>400$ & $\begin{array}{c}\mathrm{H}_{2} \text { at } 59.48 \mu \mathrm{mol} \cdot \mathrm{h}^{-1} \text { with } \\
\text { sacrificial agent }\end{array}$ & $\begin{array}{l}100 \mathrm{mg} \text { catalyst in } 210 \mathrm{~mL} \text { of } \\
\text { methanol solution }\end{array}$ & {$[70]$} \\
\hline $\begin{array}{c}\mathrm{GdCrO}_{3}-\mathrm{Gd}_{2} \mathrm{Ti}_{2} \mathrm{O}_{7} \\
\text { composite }\end{array}$ & $>420$ & $\begin{array}{c}\mathrm{H}_{2} \text { at } 246.3 \mu \mathrm{mol} \cdot \mathrm{h}^{-1} \text { with } \\
\text { sacrificial agent }\end{array}$ & $\begin{array}{l}\quad 4.1 \% \text { apparent quantum } \\
\text { efficiency, methanol solution }\end{array}$ & {$[71]$} \\
\hline $\mathrm{CoTiO}_{3}$ & $>420$ & $\begin{array}{c}\mathrm{O}_{2} \text { at } 64.6 \mu \mathrm{mol} \cdot \mathrm{h}^{-1} \text { with } \\
\text { sacrificial agent }\end{array}$ & $\begin{array}{c}100 \mathrm{mg} \text { in } 100 \mathrm{~mL} 0.04 \mathrm{M} \mathrm{AgNO}_{3} \\
\text { and } \mathrm{La}_{2} \mathrm{O}_{3} \text { solution, } 420 \mathrm{~nm}\end{array}$ & {$[57]$} \\
\hline
\end{tabular}

\subsection{Tantalate Perovskites}

Alkali tantalates are particularly known for efficient overall water splitting reaction under UV irradiation as they possess both VB and CB potentials suitable for water splitting reaction [72-74]. To enable visible light photocatalysis, doping of various elements has been studied to achieve visible light activity.

\subsection{1. $\mathrm{NaTaO}_{3}$}

Our group reported a detailed study on $\mathrm{Bi}$-doped $\mathrm{NaTaO}_{3}$ and showed that the bismuth doping site significantly affects the photocatalytic activity for hydrogen evolution [75,76]. Further, co-doping of La-Co, La-Cr, La-Ir, La-Fe in $\mathrm{NaTaO}_{3}$ have shown successful visible light absorption and subsequent hydrogen evolution [77-81]. Co-doping of $\mathrm{La}-\mathrm{N}$ in $\mathrm{NaTaO}_{3}$ has been studied for hydrogen evolution by Zhao et al. [82]. These studies have indicated that both anion and cation doping in $\mathrm{NaTaO}_{3}$ is useful for visible light photocatalytic applications. Among the doped $\mathrm{NaTaO}_{3}$ systems, computational studies on the anionic $(\mathrm{N}, \mathrm{F}, \mathrm{P}, \mathrm{Cl}, \mathrm{S})$ doping were reported by Han et al. which shows that certain anions like 
$\mathrm{N}$ and $\mathrm{P}$ may be useful for visible light absorption [83]. Additionally, doping of magnetic cations such as $\mathrm{Mn}, \mathrm{Fe}$, and $\mathrm{Co}$ in $\mathrm{NaTaO}_{3}$ has also been studied using DFT-PBE [84]. Recently, our group studied DFT calculations of a number of doped $\mathrm{NaTaO}_{3}$-based photocatalysts by PBE0 hybrid calculations (Figure 9) [85]. Further, anion doping was also explored in detail using (HSE06) hybrid DFT calculations, where $\mathrm{N}, \mathrm{P}, \mathrm{C}$, and $\mathrm{S}$ doping at $\mathrm{O}$ sites were studied. The study also reports the thermodynamics and effect of coupling between N-N, C-S, and P-P on the optical and electronic properties [86]. DFT studies are useful in explaining the properties of existing materials systems and designing new materials. Particularly, use of hybrid functional such as PBE0 or HSE06, is able to accurately define the valence band structure and location of bands or energy states that are crucially important for visible light driven photocatalysis. Hybrid DFT calculations could be useful in predictive modeling, where, band gaps and band edge potential of useful doped photocatalysts are identified. An example of doped tantalate systems is shown in Figure 9.

Figure 9. Estimated band gaps and band edge potentials of doped and co-doped $\mathrm{NaTaO}_{3}$ systems: DFT study to design novel photocatalyst [85]

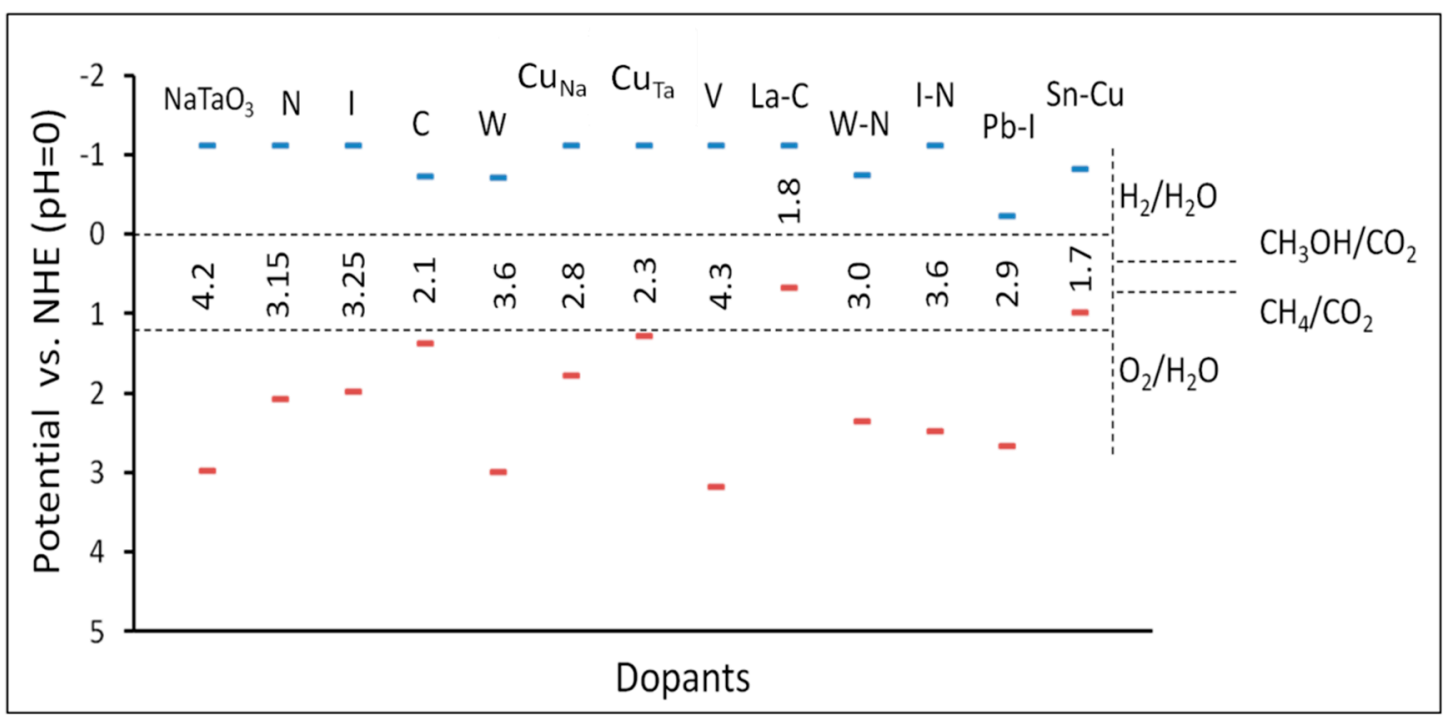

\subsection{2. $\mathrm{AgTaO}_{3}$}

$\mathrm{AgTaO}_{3}$ exhibits similar behavior to alkali tantalates, however, it has a smaller band gap value of $3.4 \mathrm{eV} . \mathrm{AgTaO}_{3}$ doped with $30 \% \mathrm{Nb}$ absorbs visible radiation and shows a stoichiometric overall water splitting reaction under visible light when loaded with $\mathrm{NiO}$ co-catalyst [87]. Co-doping of $\mathrm{N}-\mathrm{H}$ and N-F in $\mathrm{AgTaO}_{3}$ has been studied in detail. The study indicates that co-doping not only balances the charges but also improves the carrier mobility. N-F co-doped $\mathrm{AgTaO}_{3}$ has an effective band gap value of $2.9 \mathrm{eV}$ and shows $\mathrm{H}_{2}$ generation under visible light [88].

\subsection{3. $\mathrm{KTaO}_{3}$}

$\mathrm{KTaO}_{3}\left(\mathrm{Eg}_{\mathrm{g}} 3.6 \mathrm{eV}\right)$ photocatalysts have been studied for water splitting under UV radiation. However, work on development of visible light driven $\mathrm{KTaO}_{3}$ based photocatalysts is limited. 


\subsection{Vanadium and Niobium Based Perovskites}

Similar to tantalum (Ta)-based photocatalysts, Niobium ( $\mathrm{Nb}$ )-based photocatalysts show good photocatalytic activity under UV irradiation.

\subsection{1. $\mathrm{KNbO}_{3}$ and $\mathrm{NaNbO}_{3}$}

Both $\mathrm{KNbO}_{3}\left(\mathrm{Eg}_{\mathrm{g}} 3.14 \mathrm{eV}\right)$ and $\mathrm{NaNbO}_{3}\left(\mathrm{Eg}_{\mathrm{g}} 3.08 \mathrm{eV}\right)$ have band gap values in the UV-responsive region, however suitable modifications of the band structure have resulted in visible light photocatalysis [89]. $\mathrm{N}$-doped $\mathrm{NaNbO}_{3}$ is a known visible light photocatalyst for the degradation of 2-propanol [90]. Nitrogen doping in $\mathrm{KNbO}_{3}$ has been studied for water splitting as well as organic pollutant degradation [91]. First principles calculations predict that co-doping of La and Bi would induce visible light response in $\mathrm{NaNbO}_{3}$ [92]. Recent work on ferroelectric perovskites of $\mathrm{KNbO}_{3}-\mathrm{BaNiNbO}_{3}$ shows that the solid solution of these compounds could absorb six times more light and shows fifty times more photocurrent than others [93]. Although photocatalytic properties are not known, this is an attractive candidate for visible light driven photocatalyst.

\subsection{2. $\mathrm{AgNbO}_{3}$}

Replacing an A site alkali metal by silver reduces the band gap of the perovskite and $\mathrm{AgNbO}_{3}$ has a band gap of around $2.7 \mathrm{eV}$. Studies have shown that the photocatalytic activity of $\mathrm{AgNbO}_{3}$ strongly depends on the shape of the particles: polyhedron-shaped particles are favorable for $\mathrm{O}_{2}$ evolution reactions [94]. Further, La doping was found to enhanced the hotocatalytic performance by 12 -fold for gaseous 2-propenol degradation [95].

\subsection{3. $\mathrm{AgVO}_{3}$}

$\mathrm{AgVO}_{3}$ exists in two types of crystal structures, viz. $\alpha-\mathrm{AgVO}_{3}(\mathrm{Eg} 2.5 \mathrm{eV})$ and $\beta-\mathrm{AgVO}_{3}$ $\left(E_{g} 2.3 \mathrm{eV}\right.$ ) [96]. Both phases are photocatalytically active. However, $\beta-\mathrm{AgVO}_{3}$ shows better photocatalytic performance than the $\alpha$-phase. The $\mathrm{CB}$ potential of $\mathrm{AgVO}_{3}$ is not sufficient for $\mathrm{H}_{2}$ evolution, but it is suitable for the degradation of volatile organic compounds (VOCs) and $\mathrm{O}_{2}$ evolution. $\beta-\mathrm{AgVO}_{3}$ nanowires show excellent photocatalytic performance in the degradation of $\mathrm{Rh} \mathrm{B}$ [97]. Composites of $\mathrm{AgBr}-\mathrm{AgVO}_{3}$ were reported to display respectable efficiency for $\mathrm{Rh} \mathrm{B}$ degradation [98], while Ag-loaded $\mathrm{AgVO}_{3}$ has shown good performance for degradation of bisphenol [99].

\subsection{4. $\mathrm{CuNbO}_{3}$}

$\mathrm{CuNbO}_{3}$ crystallizes in the monoclinic structure and has a band gap of $2.0 \mathrm{eV}$. It is an intrinsic p-type semiconductor and has shown 5\% efficiency for photon to electron conversion when used as a photocathode. Being a stable material under irradiation, more investigations should be carried out on this material [100]. Tantalum, niobium, and vanadium belong to the same group in the periodic table. Perovskite compounds of these elements show decreasing band gap and CB potential values. This trend is attributed to the $3 \mathrm{~d}, 4 \mathrm{~d}$ and $5 \mathrm{~d}$ orbital energies in $\mathrm{V}, \mathrm{Nb}$ and $\mathrm{Ta}$, respectively. 


\subsection{Ferrite Perovskites}

Most of the ferrite perovskites have their native band gaps in the visible region. Hematite and other iron oxide compounds have known shortcomings such as short exciton diffusion length, low electron conductivity, and lower conduction band edge potential [101]. However certain ferrite-based perovskites have shown good photocatalytic activities, circumventing the shortcomings seen in binary iron oxides.

\subsection{1. $\mathrm{LaFeO}_{3}$}

$\mathrm{LaFeO}_{3}(\mathrm{Eg} 2.1 \mathrm{eV})$ has been explored for degradation of pollutants as well as hydrogen evolution under visible light. Sol-gel synthesized $\mathrm{LaFeO}_{3}$ loaded with $\mathrm{Pt}$ co-catalyst showed high yield of hydrogen evolution $\left(3,315 \mu \mathrm{mol} \cdot \mathrm{h}^{-1} \cdot \mathrm{g}^{-1}\right.$, in the presence of ethanol) under $400 \mathrm{~W}$ tungsten light source [68]. Another study on this phase demonstrates high yield of $\mathrm{H}_{2}$ and $\mathrm{O}_{2}(1290 \mu \mathrm{mol}$ and $640 \mu \mathrm{mol}$ after three hours, respectively), without any co-catalyst loading [102]. Further, Thirumalairajan et al. showed shape dependent photocatalytic activity of $\mathrm{LaFeO}_{3}$ for $\mathrm{Rh} \mathrm{B}$ dye under visible light (>400 nm) [103]. Doping of $\mathrm{Mn}$ in $\mathrm{LaFeO}_{3}$ has also been studied and it shows higher photocatalytic activity [104]. Lanthanum ferrite has demonstrated excellent photocatalytic activity under visible irradiation; however, studies on the fundamental photophysical properties are lacking the literature. Understanding the reasons why $\mathrm{LaFeO}_{3}$ is a better photocatalyst that $\mathrm{Fe}_{2} \mathrm{O}_{3}$, in terms of comparative electronic properties such as electron-hole separation, mobility, photoexcited lifetimes etc. is important for further development in ferrite-based photocatalyst.

\subsection{2. $\mathrm{BiFeO}_{3}$}

$\mathrm{BiFeO}_{3}$ is a known ferroelectric material with a band gap of $2.3 \mathrm{eV}$. Recent studies have shown that $\mathrm{BiFeO}_{3}$ could be used as a visible light photocatalyst [105]. The ferroelectric properties of $\mathrm{BiFeO}_{3}$ could be utilized to enhance the electron-hole separation and improve the photocatalytic activity. Figure 10 shows the effect of polarization on the band bending of $\mathrm{BiFeO}_{3}$ particles. Band bending affects the separation of electrons and holes in the space charge region and thus affects the photocatalytic activity. Gd-doped $\mathrm{BiFeO}_{3}$ show enhanced photocatalytic degradation for rhodamine $\mathrm{B}$ degradation attributed to its ferromagnetic behavior [106]. $\mathrm{Ca}$ doping in $\mathrm{BiFeO}_{3}$ leads to improved performance for photocatalytic degradation of Congo Red dye [107].

In another study, cations such as $\mathrm{Y}, \mathrm{Mg}$ and $\mathrm{Al}$ were doped in $\mathrm{BiFeO}_{3}$ and their photocatalytic performance was evaluated by degradation of $\mathrm{Rh} B$ under $400 \mathrm{~nm}$ radiation. The degradation performance was limited to $\mathrm{C} / \mathrm{C}_{0}$ of 0.8 within three hours [108]. The study of the effects of ferroelectric behavior on photocatalytic performance is a relatively new topic and it generally shows impressive activity for the degradation of organic pollutants, however, more experimental evidence and understanding are needed to establish a correlation between ferroelectric behavior and photocatalytic activity. Further studies on the stability and toxicity of bismuth-based materials should be carried out for realizing their practical applications. It is further noted that the tilting of octahedra in the perovskite crystal structure significantly affects its electronic properties. Nevertheless, the effect of tilting of octahedra on the photophysical properties such as electron-hole separation, electron transport, 
delocalization of charges has not been studied in detail. Such studies will prove useful in establishing the importance of perovskites in the field of photocatalysis.

Figure 10. Schematics of changes to band diagram upon polarization of $\mathrm{Gd}$ doped $\mathrm{BiFeO}_{3}$ due to ferroelectricity [106].

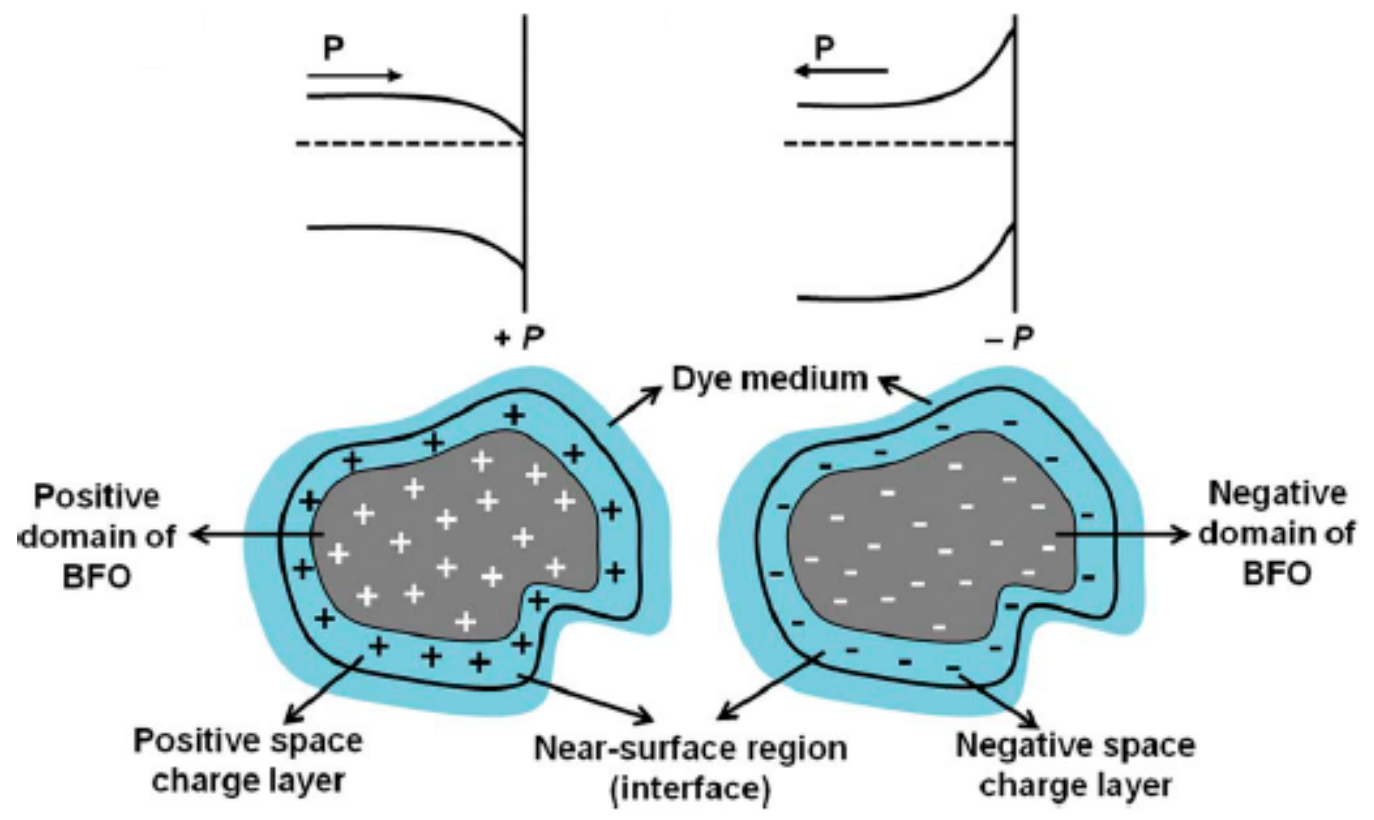

\subsection{3. $\mathrm{GaFeO}_{3}$}

$\mathrm{GaFeO}_{3}$ has been reported to show overall water splitting without any co-catalyst loading under visible light $(\lambda>395 \mathrm{~nm})$ [109]. The authors also reported a yield of 0.10 and $0.04 \mu \mathrm{mol} \cdot \mathrm{h}^{-1}$ under a $450 \mathrm{~nm}$ band pass filter. It is worth noting that the catalytic activity decreased due to deactivation of the catalyst.

\subsection{4. $\mathrm{YFeO}_{3}$}

Among the other ferrites, $\mathrm{YFeO}_{3}$ has a band gap value of $2.43 \mathrm{eV}$ and showed photocatalytic activity four times that of $\mathrm{TiO}_{2}-\mathrm{P} 25$ under $>400 \mathrm{~nm}$ visible light radiation ( $\mathrm{Rh} \mathrm{B}$ degradation) [110]

\subsection{5. $\mathrm{PrFeO}_{3}$}

$\mathrm{PrFeO}_{3}$ was evaluated for hydrogen evolution reaction from ethanol-water mixture and showed a yield of $2847 \mu \mathrm{mol} \cdot \mathrm{g}^{-1} \cdot \mathrm{h}^{-1}$ under $200 \mathrm{~W}$ tungsten lamp irradiation [69].

\subsection{6. $\mathrm{AlFeO}_{3}$}

Composites of $\mathrm{AlFeO}_{3}$ and $\mathrm{TiO}_{2}$ are reported to yield the sunlight driven photocatalytic degradation of methyl orange (MO) and eosin dye [111]. Ferrite based perovskites also offer advantage of magnetic recovery of the particles which is useful in practical applications. 


\subsection{Other Perovskite Systems}

Among the other perovskite photocatalysts, compounds of bismuth, cobalt, nickel, and antimony (occupying B sites) have band gap values in the visible region. Pentavalent bismuth perovskites are known to be active photocatalysts under visible light radiation. Perovskites such as $\mathrm{LiBiO}_{3}$ $\left(\mathrm{E}_{\mathrm{g}} 1.63 \mathrm{eV}\right), \mathrm{NaBiO}_{3}\left(\mathrm{E}_{\mathrm{g}} 2.53 \mathrm{eV}\right), \mathrm{KBiO}_{3}\left(\mathrm{Eg}_{\mathrm{g}} 2.04 \mathrm{eV}\right)$, and $\mathrm{AgBiO}_{3}\left(\mathrm{Eg}_{\mathrm{g}} 2.5 \mathrm{eV}\right)$ have all been investigated for degradation of organic pollutants [112]. $\mathrm{NaBiO}_{3}$ shows better photocatalytic performance for phenol and methylene blue (MB) degradation as compared to other $\mathrm{Bi}^{5+}$ containing perovskites as well as $\mathrm{P} 25-\mathrm{TiO}_{2}$ [112]. $\mathrm{NaBiO}_{3}$ is also reported to have higher photocatalytic activity than N-doped $\mathrm{TiO}_{2}$ photocatalyst [113]. $\mathrm{NaBiO}_{3}$ and $\mathrm{BiOCl}$ composites have been studied for enhanced electron-hole separation and subsequent photocatalysis [114]. $\mathrm{AgBiO}_{3}$ was shown to be effective in restricting the growth of Microcystis aeruginosa under simulated solar light [115]. This study shows that $\mathrm{AgBiO}_{3}$ with band gap energy around $2.5 \mathrm{eV}$ could be a potential algaecide under natural light. DFT studies show that $\mathrm{NaBiO}_{3}$ has a strong band dispersion arising from $\mathrm{Na} 3 \mathrm{~s}$ and $\mathrm{O} 2 \mathrm{p}$ hybridized orbitals, which contributes to the higher photocatalytic activity [112]. $\mathrm{LaCoO}_{3}$ has a band gap value of $2.7 \mathrm{eV}$ and oxygen deficient $\mathrm{LaCoO}_{3}\left(\mathrm{LaCoO}_{3}-\delta\right)$ has been studied for $\mathrm{MO}$ degradation $(>400 \mathrm{~nm})$ [116].

Other compounds such as $\mathrm{LaNiO}_{3}$ has been studied for $\mathrm{MO}$ degradation using wavelengths greater than $400 \mathrm{~nm}$ [117]. $\mathrm{Cu}$ doping in $\mathrm{LaNiO}_{3}$ has been studied for improved $\mathrm{H}_{2}$ evolution [118]. Ilmenite type $\mathrm{AgSbO}_{3}$ has an absorption edge onset at $480 \mathrm{~nm}$, and it has been demonstrated for $\mathrm{O}_{2}$ evolution under sacrificial agent as well as degradation of MB, RhB, and 4-chlorophenol [119]. Further, solid solution of $\mathrm{LaCrO}_{3}$ and $\mathrm{Na}_{0} \mathrm{La}_{0.5} \mathrm{TiO}_{3}$ was developed for hydrogen evolution [120]. Recently, $\mathrm{Gd}_{2} \mathrm{Ti}_{2} \mathrm{O}_{7} / \mathrm{GdCrO}_{3}$ composite was reported as photocatalyst p-n junction photocatalyst [71]. The study shows that $\mathrm{GdCrO}_{3}$ has a band gap of $2.5 \mathrm{eV}$ and is responsible for the visible light absorption [72].

\section{Complex Perovskite Materials}

\subsection{Double Perovskites}

Compounds with general formula $\mathrm{A}_{2} \mathrm{~B}_{2} \mathrm{O}_{6}$ belong to the double perovskites and they have similar crystal structures to simple perovskites. Double perovskites have the basic framework of corner connected $\mathrm{BO}_{6}$ octahedra and $\mathrm{A}$ cations enclosed within, however, the connectivity of the octahedra may differ from structure to structure. Double perovskites could accommodate different cations at the $\mathrm{A}$ or/and $\mathrm{B}$ sites, taking a general form $\mathrm{AA}^{\prime} \mathrm{BB}^{\prime} \mathrm{O}_{6}$. Accommodation of different cations at the A and $\mathrm{B}$ sites alters the photophysical properties of the compound significantly. Among the binary oxides, only a few compounds are known to have band gap values in the visible region (narrow gap), e.g., $\mathrm{Fe}_{2} \mathrm{O}_{3}$, $\mathrm{WO}_{6}, \mathrm{CuO}, \mathrm{Bi}_{2} \mathrm{O}_{3}$. However, these materials suffer from insufficient $\mathrm{CB}$ potential for hydrogen evolution. Some of the materials also suffer from poor stability and low mobility of photoexcited charges. On the other hand, many of the binary oxides are known to be efficient photocatalysts, however only activated by UV radiation (wide gap). Complex compounds offer a possibility of combining the elements from 'narrow gap' and 'wide gap' binary compounds to exploit the properties of both types of oxides, and thus are potentially useful as visible light photocatalysts. The following section reviews photocatalytic properties of double perovskites which are visible light active. 


\subsection{1. $\mathrm{Sr}_{2} \mathrm{FeNbO}_{6}$}

$\mathrm{Sr}_{2} \mathrm{FeNbO}_{6}$ has a cubic crystal structure and a band gap of $2.06 \mathrm{eV}$. In its pristine form, it is a known photocatalyst, while 7\% $\mathrm{Ti}$ doping at $\mathrm{Fe}$ site has shown two time enhancement of the hydrogen generation in methanol solution. A total of $28.5 \mu \mathrm{mol} \cdot \mathrm{h}^{-1}$ and $650 \mu \mathrm{mol} \cdot \mathrm{h}^{-1}$ were reported in presence of sacrificial agents and with $0.2 \% \mathrm{Pt}$ as co-catalyst [121]. W doping in $\mathrm{Sr}_{2} \mathrm{FeNbO}_{6}$ has also been studied and demonstrated enhancement to hydrogen evolution under visible radiation [122].

\subsection{2. $\mathrm{La}_{2} \mathrm{FeTiO}_{6}$}

$\mathrm{Hu}$ et al. reported higher photocatalytic activity for $\mathrm{La}_{2} \mathrm{FeTiO} 6$ than for $\mathrm{LaFeO}_{3}$ for degradation of p-chlorophenol under visible light irradiation [123].

\subsubsection{Other Double Perovskites}

Rare earth and bismuth-based double perovskites were studied for visible light photocatalysis. Compounds with general formula $\mathrm{Ba}_{2} \mathrm{RBiO}_{6},(\mathrm{R}=\mathrm{La}, \mathrm{Ce}, \mathrm{Pr}, \mathrm{Nd}, \mathrm{Sm}, \mathrm{Eu}, \mathrm{Gd}, \mathrm{Dy})$, were prepared and their photocatalytic activity was studied for MB degradation [124]. Authors found rare earth cation dependent photocatalytic performance, where compounds such as $\mathrm{Ba}_{2} \mathrm{EuBiO}_{6}, \mathrm{Ba}_{2} \mathrm{SmBiO}_{6}$, and $\mathrm{Ba}_{2} \mathrm{CeBiO}_{6}$ showed high photocatalytic activity. Complex perovskites such as $\mathrm{CaCu}_{3} \mathrm{Ti}_{4} \mathrm{O}_{12}$ have also been studied for their photocatalytic performance. $\mathrm{CaCu}_{3} \mathrm{Ti}_{4} \mathrm{O}_{12}$ was found to possess an indirect band gap of $1.27 \mathrm{eV}$ and $\mathrm{Pt}$-loaded $\mathrm{CaCu}_{3} \mathrm{Ti}_{4} \mathrm{O}_{12}$ shows degradation of $\mathrm{MO}$ under radiation greater than $420 \mathrm{~nm}$ [125]. Photophysical properties of certain double perovskite compounds have been reported, however, more efforts are needed to investigate photocatalytic properties of these materials. Compounds such as $\mathrm{Ba}_{2} \mathrm{CoWO}_{6}, \mathrm{Ba}_{2} \mathrm{NiWO}_{6}, \mathrm{Sr}_{2} \mathrm{CoWO}_{6}$ and $\mathrm{Sr}_{2} \mathrm{NiWO}_{6}$ are stable perovskites compounds for $\mathrm{O}_{2}$ evolution using sacrificial agents [126].

Certain tantalum-based compounds have been studied for degradation of organic compounds. $\mathrm{N}$-doped $\mathrm{K}_{2} \mathrm{Ta}_{2} \mathrm{O}_{6}$ is known to absorb visible light up to $600 \mathrm{~nm}$ and degrade formaldehyde under visible light [127]. Our group demonstrated that $\mathrm{Bi}$ doping in $\mathrm{Na}_{2} \mathrm{Ta}_{2} \mathrm{O}_{6}$ causes visible light absorption and degradation of MB [128]. Although some work has been done with double perovskites as photocatalysts, understanding of their fundamental properties is limited. More work is needed to discover their advantages as visible light photocatalyst and develop novel materials systems.

\subsection{Mixed Oxides}

Mixture of oxides and nitrides or oxides and sulphides has been developed to engineer the band structure of the oxide photocatalysts suitable for the visible light absorption. Oxynitride and oxysulphide photocatalysts offer distinctive advantages over their doped counterparts. Earlier reports on oxynitrides have revealed that replacing oxygen by nitrogen at lattice sites, in a stoichiometric manner, narrows the band gap of the oxide, by pushing the VBM into the band gap [129]. Such a modification does not produce native point defects, which would otherwise be introduced in the case of $\mathrm{N}$ doping. Stoichiometric incorporation of nitrogen also avoids the localized states induced by $\mathrm{N}$ doping and reduces the possible electron-hole recombination. Similar composition containing mixtures of sulfur and oxygen i.e., oxysulfides, has been developed for photocatalysts. Mixed oxysulfide 
perovskites of $\mathrm{Sm}_{2} \mathrm{Ti}_{2} \mathrm{~S}_{2} \mathrm{O}_{5}\left(\mathrm{Eg}_{\mathrm{g}} 2.0 \mathrm{eV}\right)$ is known for water oxidation and reduction reaction for oxygen and hydrogen evolution, respectively in presence of sacrificial agents under low photon energy wavelengths of $650 \mathrm{~nm}$. The band structure of this phase reveals that the presence of sulphur narrows the band gap and enables visible light absorption [130].

Oxynitride compounds such as $\mathrm{CaNbO}_{2} \mathrm{~N}, \mathrm{SrNbO}_{2} \mathrm{~N}, \mathrm{BaNbO}_{2} \mathrm{~N}$, and $\mathrm{LaNbON}_{2}$ belong to the perovskite type crystal structures [131]. Photocatalytic hydrogen evolution has been reported under visible light from methanol solution. $\mathrm{SrNbO}_{2} \mathrm{~N}(\mathrm{Eg} 1.8 \mathrm{eV})$ has been investigated in detail, where the photoelectrode of $\mathrm{SrNbO}_{2} \mathrm{~N}$ on a transparent conducting surface shows water oxidation reaction under no external bias [132]. Tantalum counterparts of these compounds were developed and utilized in the $\mathrm{Z}$ scheme photocatalysis. Compounds such as $\mathrm{CaTaO}_{2} \mathrm{~N}$ and $\mathrm{BaTaO}_{2} \mathrm{~N}$ were loaded with $\mathrm{Pt}$ co-catalyst and coupled with $\mathrm{pt} / \mathrm{WO}_{3}$ for $\mathrm{Z}$ scheme water splitting [133]. A solid solution of $\mathrm{BaTaO}_{2} \mathrm{~N}$ and $\mathrm{BaZrO}_{3}$ was formulated for hydrogen and oxygen evolution, which showed improved performance compared with the individual photocatalysts under visible light [134]. $\mathrm{LaTiO}_{x} \mathrm{~N}_{y}$ is another perovskite type compound which shows high photocurrent density under visible light [135].

Apart from the double perovskites belonging to the general formula $\mathrm{AA}^{\prime} \mathrm{BB}^{\prime} \mathrm{O}_{6}$, there are a several other compounds that show crystal structures close to the perovskite type structure, however such compounds are not included in the current review. Theoretically, double perovskites offer a wider scope to design photocatalysts by selecting suitable cations and $\mathrm{AA}^{\prime}$ and $\mathrm{BB}^{\prime}$ sites in the lattice. Work on design and development of double perovskite is currently limited and synthesis and characterization of new materials in this category are needed.

\section{Summary and Outlook}

A large number of perovskite-based compounds (over 80) have been studied for visible light driven photocatalytic applications. Perovskite structures offer abundant scope in designing novel compounds based on A and B site occupancy, which gives rise to a wide range of materials systems with unique properties. Among these compounds, photocatalysts with pristine band gaps in the visible region such as $\mathrm{LaFeO}_{3}, \mathrm{PrFeO}_{3}, \mathrm{NaBiO}_{3}$, and $\mathrm{AgBiO}_{3}$ (Table 2) show promising photocatalytic performance under visible radiation $(>400 \mathrm{~nm})$. Although there are reports on the photocatalytic activity of these compounds, detailed studies on these materials are limited. More efforts are needed to understand the structure-property relations in such ferrites and bismuth based compounds and improve their photocatalytic activity. Among the wide band gap semiconductors, $\mathrm{SrTiO}_{3}$ - and $\mathrm{NaTaO}_{3}-$ based photocatalysts are the most investigated systems. The strategy of doping foreign elements in wide band gap photocatalysts is widely used to induce visible light absorption and subsequently to enable photocatalytic activity. Nonetheless, very limited knowledge is available on the adverse effect of dopants on the photophysical properties of the compounds (e.g., if the benefit derived from dopant-induced visible light activity is overweighed by a loss of UV light activity). This should be properly investigated in the future. Appropriate dopants which retain the beneficial properties of the host materials while inducing visible light responses should be identified. Research work on complex perovskites show that these compounds offer distinct advantages as compared with simple perovskites. Designing complex perovskite compounds with suitable elements at A and B sites to yield desired photocatalytic properties is a challenge. We expect computational design would help shorten the 
selection process. Recent advances in computational tools such as DFT based band structure calculations are highly effective to design and understand novel materials systems.

Table 2. Compilation of promising photocatalytic systems for organic compounds degradation under visible light.

\begin{tabular}{cccc}
\hline $\begin{array}{c}\text { Materials } \\
\text { System }\end{array}$ & $\begin{array}{c}\text { Band Gap } \\
(\mathbf{e V})\end{array}$ & Photocatalytic Tests Reported & Ref. \\
\hline${\mathrm{Ga} \mathrm{doped} \mathrm{BiFeO}_{3}}$ & $2.18-2.50$ & $\begin{array}{c}\text { Enhanced degradation of rhodamine } \mathrm{B} \text { compared to pristine } \mathrm{BiFeO}_{3} \\
\text { Nanospheres show higher rates of rhodamine B degradation than } \\
\text { nanocubes and nanorods }\end{array}$ & {$[106]$} \\
$\mathrm{LaFeO}_{3}$ & 2.10 & Rhodamine B degradation rate higher than P25 $(>400 \mathrm{~nm})$ & {$[103]$} \\
$\mathrm{YFeO}_{3}$ & 2.43 & Bleaching rate of Methylene Blue higher than N doped $\mathrm{TiO}_{2} .(>400 \mathrm{~nm})$ & {$[110]$} \\
$\mathrm{NaBiO}_{3}$ & 2.60 & Eddicient degradation of Rh B. MB, 4-chlorophenol $(>420 \mathrm{~nm})$ & {$[119,136]$} \\
$\mathrm{AgSbO}_{3}$ & 2.58 & Inhibition of Microcystis & {$[115]$} \\
$\mathrm{AgBiO}_{3}$ & 2.50 & &
\end{tabular}

As certain perovskite compounds exhibit ferroelectric, ferromagnetic, or piezoelectric effects, there is a need to understand the correlation between these effects and the photocatalytic activity to a greater depth. Such studies would certainly be helpful in the development of efficient visible light photocatalysts. On a final note, there has been significant progress in the development of visible light perovskites in the past years. This development has laid a good foundation for future work in this area. Further understanding of the crystal and electronic structural factors behind photocatalytic activity is needed for the future development of efficient visible light-driven perovskites.

\section{Acknowledgments}

Financial support through an SUG grant from the College of Engineering, Nanyang Technological University, Singapore is greatly appreciated.

\section{Author Contributions}

P.K. performed literature research, analysis, and drafted the paper. C.Z. initiated and supervised the work and provided insights. Both authors revised and approved the final manuscript.

\section{Conflicts of Interest}

The authors declare no conflict of interest.

\section{References}

1. Maeda, K. Photocatalytic water splitting using semiconductor particles: History and recent developments. J. Photchem. Photobiol. C 2011, 12, 237-268.

2. Qu, Y. Duan, X. Progress, challenge and perspective of heterogeneous photocatalysts. Chem. Soc. Rev. 2013, 42, 2568-2580.

3. Hou, W.; Cronin, S.B. A Review of Surface Plasmon Resonance-Enhanced Photocatalysis. Adv. Funct. Mat. 2013, 23, 1612-1619. 
4. Osterloh, F.E. Inorganic nanostructures for photoelectrochemical and photocatalytic water splitting. Chem. Soc. Rev. 2013, 42, 2294-2320.

5. Cook, T.R.; Dogutan, D.K.; Reece, S.Y.; Surendranath, Y.; Teets, T.S.; Nocera, D.G. Solar energy supply and storage for the legacy and nonlegacy worlds. Chem. Rev. 2010, 110, 6474-6502.

6. Izumi, Y. Recent advances in the photocatalytic conversion of carbon dioxide to fuels with water and/or hydrogen using solar energy and beyond. Coord. Chem. Rev. 2013, 257, 171-186.

7. Tahir, M.; Amin, N.S. Recycling of carbon dioxide to renewable fuels by photocatalysis: Prospects and challenges. Renew. Sust. Energy Rev. 2013, 25, 560-579.

8. Tan, Y.N.; Wong, C.L.; Mohamed, A.R. An Overview on the Photocatalytic Activity of Nano-Doped-TiO 2 in the Degradation of Organic Pollutants. ISRN Mat. Sci. 2011, 2011, 18.

9. Pelaez, M.; Nolan, N.T.; Pillai, S.C.; Seery, M.K.; Falaras, P.; Kontos, A.G.; Dunlop, P.S.M.; Hamilton, J.W.J.; Byrne, J.A.; O'shea, K.; et al. A review on the visible light active titanium dioxide photocatalysts for environmental applications. Appl. Catal. B 2012, 125, 331-349.

10. Dalrymple, O.K.; Stefanakos, E.; Trotz, M.A. Goswami, D.Y. A review of the mechanisms and modeling of photocatalytic disinfection. Appl. Catal. B 2010, 98, 27-38.

11. Zhang, Z.; Gamage, J. Applications of photocatalytic disinfection. Int. J. Photoenergy 2010, doi:10.1155/2010/764870.

12. Konstantinou, I.K.; Albanis, T.A. $\mathrm{TiO}_{2}$-assisted photocatalytic degradation of azo dyes in aqueous solution: Kinetic and mechanistic investigations: A review. Appl. Catal. B 2004, 49, 1-14.

13. Ahmed, S.; Rasul, M.G.; Martens, W.; Brown, R.; Hashib, M.A. Advances in Heterogeneous Photocatalytic Degradation of Phenols and Dyes in Wastewater: A Review. Water Air Soil Pollut. 2011, 215, 3-29.

14. Rajesh, J.T.; Praveen, K.S.; Ramchandra, G.K.; Raksh, V.J. Photocatalytic degradation of dyes and organic contaminants in water using nanocrystalline anatase and rutile $\mathrm{TiO}_{2}$. Sci. Technol. Adv. Mat. 2007, 8, 455.

15. Bickley, R.I.; Vishwanathan, V. Photocatalytically induced fixation of molecular nitrogen by near UV radiation. Nature 1979, 280, 306-308.

16. Guo, C.; Wu, X.; Yan, M.; Dong, Q.; Yin, S.; Sato, T.; Liu, S. The visible-light driven photocatalytic destruction of NOx using mesoporous $\mathrm{TiO} 2$ spheres synthesized via a "water-controlled release process". Nanoscale 2013, 5, 8184-8191.

17. Zhao, J.; Yang, X. Photocatalytic oxidation for indoor air purification: A literature review. Build. Environ. 2003, 38, 645-654.

18. Lasek, J.; Yu, Y.-H.; Wu, J.C.S. Removal of NOx by photocatalytic processes. J. Photchem. Photobiol. C 2013, 14, 29-52.

19. Wang, H.; Wu, Z.; Zhao, W.; Guan, B. Photocatalytic oxidation of nitrogen oxides using $\mathrm{TiO}_{2}$ loading on woven glass fabric. Chemosphere 2007, 66, 185-190.

20. Bhalla, A.S.; Guo, R.; Roy, R. The perovskite structure-a review of its role in ceramic science and technology. Mat. Res. Innov. 2000, 4, 3-26.

21. Damjanovic, D. Piezoelectric properties of perovskite ferroelectrics: unsolved problems and future research. Ann. Chim.-Sci. Mat. 2001, 26, 99-106.

22. Nuraje, N.; Su, K. Perovskite ferroelectric nanomaterials. Nanoscale 2013, 5, 8752-8780. 
23. Jia, Q.; Iwase, A.; Kudo, A. BiVO4-Ru/SrTiO $3: R h$ composite Z-scheme photocatalyst for solar water splitting. Chem. Sci. 2014, 5, 1513-1519.

24. Sayama, K.; Mukasa, K.; Abe, R.; Abe, Y.; Arakawa, H. Stoichiometric water splitting into $\mathrm{H}_{2}$ and $\mathrm{O}_{2}$ using a mixture of two different photocatalysts and an $\mathrm{IO}_{3}{ }^{-} / \mathrm{I}^{-}$shuttle redox mediator under visible light irradiation. Chem. Commun. 2001, 23, 2416-2417.

25. Zhang, W.F.; Tang, J.; Ye, J. Photoluminescence and photocatalytic properties of $\mathrm{SrSnO}_{3}$ perovskite. Chem. Phys. Lett. 2006, 418, 174-178.

26. Lin, W.H.; Cheng, C.; Hu, C.C.; Teng, H. $\mathrm{NaTaO}_{3}$ photocatalysts of different crystalline structures for water splitting into $\mathrm{H}_{2}$ and $\mathrm{O}_{2}$. Appl. Phys. Lett. 2006, 89, 211904

27. Shi, J.; Guo, L. $\mathrm{ABO}_{3}$-based photocatalysts for water splitting. Prog. Nat. Sci. Mat. Int. 2012, 22, 592-615.

28. Wang, W.N.; Soulis, J.; Jeffrey Yang, Y.; Biswas, P. Comparison of $\mathrm{CO}_{2}$ photoreduction systems: A review. Aerosol Air Qual. Res. 2014, 14, 533-549.

29. Tang, J.; Durrant, J.R.; Klug, D.R. Mechanism of Photocatalytic Water Splitting in $\mathrm{TiO}_{2}$. Reaction of Water with Photoholes, Importance of Charge Carrier Dynamics, and Evidence for Four-Hole Chemistry. J. Am. Chem. Soc. 2008, 130, 13885-13891.

30. Kudo, A.; Miseki, Y. Heterogeneous photocatalyst materials for water splitting. Chem. Soc. Rev. 2009, 38, 253-278.

31. Houas, A.; Lachheb, H.; Ksibi, M.; Elaloui, E.; Guillard, C.; Herrmann, J.-M. Photocatalytic degradation pathway of methylene blue in water. Appl. Catal. B 2001, 31, 145-157.

32. Cho, M.; Chung, H.; Choi, W.; Yoon, J. Linear correlation between inactivation of E. coli and $\mathrm{OH}$ radical concentration in $\mathrm{TiO}_{2}$ photocatalytic disinfection. Water Res. 2004, 38, 1069-1077.

33. Turchi, C.S.; Ollis, D.F. Photocatalytic degradation of organic water contaminants: Mechanisms involving hydroxyl radical attack. J. Catal. 1990, 122, 178-192.

34. Habisreutinger, S.N.; Schmidt-Mende, L.; Stolarczyk, J.K. Photocatalytic reduction of $\mathrm{CO}_{2}$ on $\mathrm{TiO}_{2}$ and other semiconductors. Angew. Chem. Int. Ed. 2013, 52, 7372-7408.

35. Rusina, O.; Linnik, O.; Eremenko, A.; Kisch, H. Nitrogen Photofixation on Nanostructured Iron Titanate Films. Chem. Eur. J. 2003, 9, 561-565.

36. Rusina, O.; Macyk, W.; Kisch, H. Photoelectrochemical Properties of a Dinitrogen-Fixing Iron Titanate Thin Film. J. Phys. Chem. B 2005, 109, 10858-10862.

37. Zhu, D.; Zhang, L.; Ruther, R.E.; Hamers, R.J. Photo-illuminated diamond as a solid-state source of solvated electrons in water for nitrogen reduction. Nat. Mater. 2013, 12, 836-841.

38. Kavan, L.; Grätzel, M.; Gilbert, S.; Klemenz, C.; Scheel, H. Electrochemical and photoelectrochemical investigation of single-crystal anatase. J. Am. Chem. Soc. 1996, 118, 6716-6723.

39. Van Benthem, K.; Elsässer, C.; French, R.H. Bulk electronic structure of $\mathrm{SrTiO}_{3}$ : Experiment and theory. J. Appl. Phys. 2001, 90, 6156-6164.

40. Townsend, T.K.; Browning, N.D.; Osterloh, F.E. Overall photocatalytic water splitting with $\mathrm{NiOx}_{-} \mathrm{SrTiO}_{3}-\mathrm{A}$ revised mechanism. Energy Environ. Sci. 2012, 5, 9543-9550.

41. Konta, R.; Ishii, T.; Kato, H.; Kudo, A. Photocatalytic Activities of Noble Metal Ion Doped $\mathrm{SrTiO}_{3}$ under Visible Light Irradiation. J. Phys. Chem. B 2004, 108, 8992-8995. 
42. Chen, H.-C.; Huang, C.-W.; Wu, J.C.S.; Lin, S.-T. Theoretical Investigation of the Metal-Doped $\mathrm{SrTiO}_{3}$ Photocatalysts for Water Splitting. J. Phys. Chem. C 2012, 116, 7897-7903.

43. Iwashina, K.; Kudo, A. Rh-Doped $\mathrm{SrTiO}_{3}$ Photocatalyst Electrode Showing Cathodic Photocurrent for Water Splitting under Visible-Light Irradiation. J. Am. Chem. Soc. 2011, 133, 13272-13275.

44. Sasaki, Y.; Kato, H.; Kudo, A. $\left[\mathrm{Co}(\text { bpy })_{3}\right]^{3+/ 2+}$ and $\left[\mathrm{Co}(\text { phen })_{3}\right]^{3+/ 2+}$ Electron Mediators for Overall Water Splitting under Sunlight Irradiation Using Z-Scheme Photocatalyst System. J. Am. Chem. Soc. 2013, 135, 5441-5449.

45. Sasaki, Y.; Nemoto, H.; Saito, K.; Kudo, A. Solar Water Splitting Using Powdered Photocatalysts Driven by Z-Schematic Interparticle Electron Transfer without an Electron Mediator. J. Phys. Chem. C 2009, 113, 17536-17542.

46. Kato, H.; Sasaki, Y.; Shirakura, N.; Kudo, A. Synthesis of highly active rhodium-doped $\mathrm{SrTiO}_{3}$ powders in Z-scheme systems for visible-light-driven photocatalytic overall water splitting. J. Mater. Chem. A 2013, 1, 12327-12333.

47. Asai, R.; Nemoto, H.; Jia, Q.; Saito, K.; Iwase, A.; Kudo, A. A visible light responsive rhodium and antimony-codoped $\mathrm{SrTiO}_{3}$ powdered photocatalyst loaded with an $\mathrm{IrO}_{2}$ cocatalyst for solar water splitting. Chem. Commun. 2014, 50, 2543-2546.

48. Jia, Y.; Shen, S.; Wang, D.; Wang, X.; Shi, J.; Zhang, F.; Han, H.; Li, C. Composite $\mathrm{Sr}_{2} \mathrm{TiO}_{4} / \mathrm{SrTiO}_{3}(\mathrm{La}, \mathrm{Cr})$ heterojunction based photocatalyst for hydrogen production under visible light irradiation. J. Mater. Chem. A 2013, 1, 7905-7912.

49. Wang, D.; Kako, T.; Ye, J. New Series of Solid-Solution Semiconductors $\left(\mathrm{AgNbO}_{3}\right)_{1-\mathrm{x}}\left(\mathrm{SrTiO}_{3}\right)_{\mathrm{x}}$ with Modulated Band Structure and Enhanced Visible-Light Photocatalytic Activity. J. Phys. Chem. C 2009, 113, 3785-3792.

50. $\mathrm{Fu}, \mathrm{Q}$; He, T.; Li, J.L.; Yang, G.W. Band-engineered $\mathrm{SrTiO}_{3}$ nanowires for visible light photocatalysis. J. Appl. Phys. 2012, 112, 104322.

51. Wunderlich, W.; Ohta, H.; Koumoto, K. Enhanced effective mass in doped $\mathrm{SrTiO}_{3}$ and related perovskites. Physica B 2009, 404, 2202-2212.

52. Maeda, K. Rhodium-Doped Barium Titanate Perovskite as a Stable p-Type Semiconductor Photocatalyst for Hydrogen Evolution under Visible Light. ACS App. Mater. Interfaces 2014, 6, 2167-2173.

53. Zhang, H.; Chen, G.; Li, Y.; Teng, Y. Electronic structure and photocatalytic properties of copper-doped $\mathrm{CaTiO}_{3}$. Int. J. Hydrog. Energy 2010, 35, 2713-2716.

54. Zhang, H.; Chen, G.; He, X.; Xu, J. Electronic structure and photocatalytic properties of Ag-La codoped $\mathrm{CaTiO}_{3}$. J. Alloys Compd. 2012, 516, 91-95.

55. Fu, Q.; Li, J.L.; He, T.; Yang, G.W. Band-engineered $\mathrm{CaTiO}_{3}$ nanowires for visible light photocatalysis. J. Appl. Phys. 2013, 113, 104303.

56. $\mathrm{Xu}, \mathrm{Y}$.; Schoonen, M.A. The absolute energy positions of conduction and valence bands of selected semiconducting minerals. Am. Miner. 2000, 85, 543-556.

57. Qu, Y.; Zhou, W.; Fu, H. Porous Cobalt Titanate Nanorod: A New Candidate for Visible Light-Driven Photocatalytic Water Oxidation. ChemCatChem 2014, 6, 265-270.

58. Rawal, S.B.; Bera, S.; Lee, D.; Jang, D.-J.; Lee, W.I. Design of visible-light photocatalysts by coupling of narrow bandgap semiconductors and $\mathrm{TiO}_{2}$ : Effect of their relative energy band positions on the photocatalytic efficiency. Catal. Sci. Technol. 2013, 3, 1822-1830. 
59. Qu, Y.; Zhou, W.; Ren, Z.; Du, S.; Meng, X.; Tian, G.; Pan, K.; Wang, G.; Fu, H. Facile preparation of porous $\mathrm{NiTiO}_{3}$ nanorods with enhanced visible-light-driven photocatalytic performance. J. Mater. Chem. 2012, 22, 16471-16476.

60. Kim, Y.J.; Gao, B.; Han, S.Y.; Jung, M.H.; Chakraborty, A.K.; Ko, T.; Lee, C.; Lee, W.I. Heterojunction of $\mathrm{FeTiO}_{3}$ Nanodisc and $\mathrm{TiO}_{2}$ Nanoparticle for a Novel Visible Light Photocatalyst. J. Phys. Chem. C 2009, 113, 19179-19184.

61. Hassan, M.A.; Amna, T.; Khil, M.-S. Synthesis of High aspect ratio $\mathrm{CdTiO}_{3}$ nanofibers via electrospinning: characterization and photocatalytic activity. Ceram. Int. 2014, 40, 423-427.

62. Li, L.; Zhang, Y.; Schultz, A.M.; Liu, X.; Salvador, P.A.; Rohrer, G.S. Visible light photochemical activity of heterostructured $\mathrm{PbTiO}_{3}-\mathrm{TiO}_{2}$ core-shell particles. Catal. Sci. Technol. 2012, 2, 1945-1952.

63. Dong, W.; Wang, D.; Jiang, L.; Zhu, H.; Huang, H.; Li, J.; Zhao, H.; Li, C.; Chen, B.; Deng, G. Synthesis of $\mathrm{F}$ doping $\mathrm{MnTiO}_{3}$ nanodiscs and their photocatalytic property under visible light. Mater. Lett. 2013, 98, 265-268.

64. Shen, P.; Lofaro, J.C., Jr.; Woerner, W.R.; White, M.G.; Su, D.; Orlov, A. Photocatalytic activity of hydrogen evolution over $\mathrm{Rh}$ doped $\mathrm{SrTiO}_{3}$ prepared by polymerizable complex method. Chem. Eng. J. 2013, 223, 200-208.

65. Kato, H.; Kudo, A. Visible-Light-Response and Photocatalytic Activities of $\mathrm{TiO}_{2}$ and $\mathrm{SrTiO}_{3}$ Photocatalysts Codoped with Antimony and Chromium. J. Phys. Chem. B 2002, 106, 5029-5034.

66. Yin, J.; Zou, Z.; Ye, J. A Novel Series of the New Visible-Light-Driven Photocatalysts $\mathrm{MCo}_{1 / 3} \mathrm{Nb}_{2 / 3} \mathrm{O}_{3}(\mathrm{M}=\mathrm{Ca}, \mathrm{Sr}$, and $\mathrm{Ba})$ with Special Electronic Structures. J. Phys. Chem. B 2003, 107, 4936-4941.

67. Xu, X.; Randorn, C.; Efstathiou, P.; Irvine, J.T.S. A red metallic oxide photocatalyst. Nat. Mater. 2012, 11, 595-598.

68. Tijare, S.N.; Joshi, M.V.; Padole, P.S.; Mangrulkar, P.A.; Rayalu, S.S.; Labhsetwar, N.K. Photocatalytic hydrogen generation through water splitting on nano-crystalline $\mathrm{LaFeO}_{3}$ perovskite. Int. J. Hydrog. Energy 2012, 37, 10451-10456.

69. Tijare, S.N.; Bakardjieva, S.; Subrt, J.; Joshi, M.V.; Rayalu, S.S.; Hishita, S.; Labhsetwar, N. Synthesis and visible light photocatalytic activity of nanocrystalline $\mathrm{PrFeO}_{3}$ perovskite for hydrogen generation in ethanol-water system. J. Chem. Sci. 2014, 126, 517-525.

70. Li, Z.; Wang, Y.; Liu, J.; Chen, G.; Li, Y.; Zhou, C. Photocatalytic hydrogen production from aqueous methanol solutions under visible light over $\mathrm{Na}\left(\mathrm{Bi}_{\mathrm{x}} \mathrm{Ta}_{1-\mathrm{x}}\right) \mathrm{O}_{3}$ solid-solution. Int. J. Hydrog. Energy 2009, 34, 147-152.

71. Parida, K.M.; Nashim, A.; Mahanta, S.K. Visible-light driven $\mathrm{Gd}_{2} \mathrm{Ti}_{2} \mathrm{O}_{7} / \mathrm{GdCrO}_{3}$ composite for hydrogen evolution. J. Chem. Soc. Dalton Trans. 2011, 40, 12839-12845.

72. Kato, H.; Asakura, K.; Kudo, A. Highly efficient water splitting into $\mathrm{H}_{2}$ and $\mathrm{O}_{2}$ over lanthanum-doped $\mathrm{NaTaO}_{3}$ photocatalysts with high crystallinity and surface nanostructure. J. Am. Chem. Soc. 2003, 125, 3082-3089.

73. Yamakata, A.I.T.A.; Kato, H.; Kudo, A.; Onishi, H. Photodynamics of $\mathrm{NaTaO}_{3}$ Catalysts for Efficient Water Splitting. J. Phys. Chem. B 2003, 107, 14383-14387.

74. Kato, H.; Kudo, A. Water splitting into $\mathrm{H}_{2}$ and $\mathrm{O}_{2}$ on alkali tantalate photocatalysts $\mathrm{ATaO}_{3}$ (A = Li, Na, and K). J. Phys. Chem. B 2001, 105, 4285-4292. 
75. Kanhere, P.D.; Zheng, J.; Chen, Z. Site Specific Optical and Photocatalytic Properties of Bi-Doped NaTaO3. J. Phys. Chem. C 2011, 115, 11846-11853.

76. Kanhere, P.; Zheng, J.; Chen, Z. Visible light driven photocatalytic hydrogen evolution and photophysical properties of $\mathrm{Bi}^{3+}$ doped $\mathrm{NaTaO}_{3}$. Int. J. Hydrog. Energy 2012, 37, 4889-4896.

77. Yi, Z.G.; Ye, J.H. Band gap tuning of $\mathrm{Na}_{1-\mathrm{x}} \mathrm{La}_{x} \mathrm{Ta}_{1-\mathrm{x}} \mathrm{Co}_{\mathrm{x}} \mathrm{O}_{3}$ solid solutions for visible light photocatalysis. App. Phys. Lett. 2007, 91, 254108.

78. Yi, Z.G.; Ye, J.H. Band gap tuning of $\mathrm{Na}_{1-x} \mathrm{La}_{x} \mathrm{Ta}_{1-\mathrm{x}} \mathrm{Cr}_{\mathrm{x}} \mathrm{O}_{3}$ for $\mathrm{H}_{2}$ generation from water under visible light irradiation. J. App. Phys. 2009, 106, 074910.

79. Yang, M.; Huang, X.; Yan, S.; Li, Z.; Yu, T.; Zou, Z. Improved hydrogen evolution activities under visible light irradiation over $\mathrm{NaTaO}_{3}$ codoped with lanthanum and chromium. Mater. Chem. Phys. 2010, 121, 506-510.

80. Iwase, A.; Saito, K.; Kudo, A. Sensitization of $\mathrm{NaMO}_{3}$ (M: $\mathrm{Nb}$ and Ta) photocatalysts with wide band gaps to visible light by Ir doping. Bull. Chem. Soc. Jpn. 2009, 82, 514-518.

81. Kanhere, P.; Nisar, J.; Tang, Y.; Pathak, B.; Ahuja, R.; Zheng, J.; Chen, Z. Electronic Structure, Optical Properties, and Photocatalytic Activities of $\mathrm{LaFeO}_{3}-\mathrm{NaTaO}_{3}$ Solid Solution. J. Phys. Chem. C 2012, 116, 22767-22773.

82. Zhao, Z.; Li, R.; Li, Z.; Zou, Z. Photocatalytic activity of $\mathrm{La}-\mathrm{N}$-codoped $\mathrm{NaTaO}_{3}$ for $\mathrm{H}_{2}$ evolution from water under visible-light irradiation. J. Phys. D Appl. Phys. 2011, 44, 165401.

83. Han, P.; Wang, X.; Zhao, Y.H.; Tang, C. Electronic structure and optical properties of non-metals (N, F, P, Cl,S)—Doped cubic $\mathrm{NaTaO}_{3}$ by density functional theory. Adv. Mater. Res. 2009, 79-82, $1245-1248$.

84. Zhou, X.; Shi, J.; Li, C. Effect of metal doping on electronic structure and visible light absorption of $\mathrm{SrTiO}_{3}$ and $\mathrm{NaTaO}_{3}(\mathrm{Metal}=\mathrm{Mn}, \mathrm{Fe}$, and Co). J. Phys. Chem. C 2011, 115, 8305-8311.

85. Kanhere, P.; Shenai, P.; Chakraborty, S.; Ahuja, R.; Zheng, J.; Chen, Z. Mono- and co-doped $\mathrm{NaTaO}_{3}$ for visible light photocatalysis. PCCP 2014, 16, 16085-16094.

86. Wang, B.; Kanhere, P.; Chen, Z.; Nisar, J.; Pathak, B.; Ahuja, R. Anion-Doped $\mathrm{NaTaO}_{3}$ for Visible Light Photocatalysis. J. Phys. Chem. C 2013, 117, 22518-22524.

87. Ni, L.; Tanabe, M.; Irie, H. A visible-light-induced overall water-splitting photocatalyst: conduction-band-controlled silver tantalate. Chem. Commun. 2013, 49, 10094-10096.

88. Li, M.; Zhang, J.; Dang, W.; Cushing, S.K.; Guo, D.; Wu, N.; Yin, P. Photocatalytic hydrogen generation enhanced by band gap narrowing and improved charge carrier mobility in $\mathrm{AgTaO}_{3}$ by compensated co-doping. PCCP 2013, 15, 16220-16226.

89. Liu, J.W.; Chen, G.; Li, Z.H.; Zhang, Z.G. Hydrothermal synthesis and photocatalytic properties of $\mathrm{ATaO}_{3}$ and $\mathrm{ANbO}_{3}(\mathrm{~A}=\mathrm{Na}$ and K). Int. J. Hydrog. Energy 2007, 32, 2269-2272.

90. Shi, H.; Li, X.; Iwai, H.; Zou, Z.; Ye, J. 2-Propanol photodegradation over nitrogen-doped $\mathrm{NaNbO}_{3}$ powders under visible-light irradiation. J. Phys. Chem. Solids 2009, 70, 931-935.

91. Wang, R.; Zhu, Y.; Qiu, Y.; Leung, C.-F.; He, J.; Liu, G.; Lau, T.-C. Synthesis of nitrogen-doped $\mathrm{KNbO}_{3}$ nanocubes with high photocatalytic activity for water splitting and degradation of organic pollutants under visible light. Chem. Eng. J. 2013, 226, 123-130.

92. Liu, G.; Ji, S.; Yin, L.; Xu, G.; Fei, G.; Ye, C. Visible-light-driven photocatalysts: $(\mathrm{La} / \mathrm{Bi}+\mathrm{N})$-codoped $\mathrm{NaNbO}_{3}$ by first principles. J. Appl. Phys. 2011, 109, 063103. 
93. Grinberg, I.; West, D.V.; Torres, M.; Gou, G.; Stein, D.M.; Wu, L.; Chen, G.; Gallo, E.M.; Akbashev, A.R.; Davies, P.K.; et al. Perovskite oxides for visible-light-absorbing ferroelectric and photovoltaic materials. Nature 2013, 503, 509-512.

94. Li, G.; Yan, S.; Wang, Z.; Wang, X.; Li, Z.; Ye, J.; Zou, Z. Synthesis and visible light photocatalytic property of polyhedron-shaped $\mathrm{AgNbO}_{3}$. J. Chem. Soc. Dalton Trans. 2009, 40, 8519-8524.

95. Li, G.; Kako, T.; Wang, D.; Zou, Z.; Ye, J. Enhanced photocatalytic activity of La-doped $\mathrm{AgNbO}_{3}$ under visible light irradiation. J. Chem. Soc. Dalton Trans. 2009, 13, 2423-2427.

96. Konta, R.; Kato, H.; Kobayashi, H.; Kudo, A. Photophysical properties and photocatalytic activities under visible light irradiation of silver vanadates. PCCP 2003, 5, 3061-3065.

97. Xu, J.; Hu, C.; Xi, Y.; Wan, B.; Zhang, C.; Zhang, Y. Synthesis and visible light photocatalytic activity of $\beta-\mathrm{AgVO}_{3}$ nanowires. Solid State Sci. 2012, 14, 535-539.

98. Sang, Y.; Kuai, L.; Chen, C.; Fang, Z.; Geng, B. Fabrication of a Visible-Light-Driven Plasmonic Photocatalyst of $\mathrm{AgVO}_{3} @ \mathrm{AgBr} @ \mathrm{Ag}$ Nanobelt Heterostructures. ACS App. Mater. Interfaces 2014, 6, 5061-5068.

99. Ju, P.; Fan, H.; Zhang, B.; Shang, K.; Liu, T.; Ai, S.; Zhang, D. Enhanced photocatalytic activity of $\beta-\mathrm{AgVO}_{3}$ nanowires loaded with $\mathrm{Ag}$ nanoparticles under visible light irradiation. Sep. Purif. Technol. 2013, 109, 107-110.

100. Joshi, U.A.; Palasyuk, A.M.; Maggard, P.A. Photoelectrochemical Investigation and Electronic Structure of a p-Type $\mathrm{CuNbO}_{3}$ Photocathode. J. Phys. Chem. C 2011, 115, 13534-13539.

101. Lin, Y.; Yuan, G.; Sheehan, S.; Zhou, S.; Wang, D. Hematite-based solar water splitting: Challenges and opportunities. Energy Environ. Sci. 2011, 4, 4862-4869.

102. Parida, K.M.; Reddy, K.H.; Martha, S.; Das, D.P.; Biswal, N. Fabrication of nanocrystalline $\mathrm{LaFeO}_{3}$ : An efficient sol-gel auto-combustion assisted visible light responsive photocatalyst for water decomposition. Int. J. Hydrog. Energy 2010, 35, 12161-12168.

103. Thirumalairajan, S.; Girija, K.; Hebalkar, N.Y.; Mangalaraj, D.; Viswanathan, C.; Ponpandian, N. Shape evolution of perovskite $\mathrm{LaFeO}_{3}$ nanostructures: A systematic investigation of growth mechanism, properties and morphology dependent photocatalytic activities. RSC $A d v$. 2013, 3, 7549-7561.

104. Wei, Z.-X.; Wang, Y.; Liu, J.-P.; Xiao, C.-M.; Zeng, W.-W.; Ye, S.-B. Synthesis, magnetization,

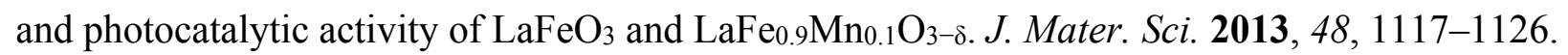

105. Gao, F.; Chen, X.Y.; Yin, K.B.; Dong, S.; Ren, Z.F.; Yuan, F.; Yu, T.; Zou, Z.G.; Liu, J.M. Visible-Light Photocatalytic Properties of Weak Magnetic $\mathrm{BiFeO}_{3}$ Nanoparticles. Adv. Mater. 2007, 19, 2889-2892.

106. Mohan, S.; Subramanian, B.; Bhaumik, I.; Gupta, P.K.; Jaisankar, S.N. Nanostructured $\mathrm{Bi}_{(1-\mathrm{x})} \mathrm{Gd}_{(\mathrm{x})} \mathrm{FeO}_{3}-\mathrm{A}$ multiferroic photocatalyst on its sunlight driven photocatalytic activity. RSC Adv. 2014, 4, 16871-16878.

107. Feng, Y.N.; Wang, H.C.; Luo, Y.D.; Shen, Y.; Lin, Y.H. Ferromagnetic and photocatalytic behaviors observed in Ca-doped $\mathrm{BiFeO}_{3}$ nanofibres. J. App. Phys. 2013, 113, 146101.

108. Madhu, C.; Bellakki, M.B.; Manivannan, V. Synthesis and characterization of cation-doped $\mathrm{BiFeO}_{3}$ materials for photocatalytic applications. Indian J. Eng. Mater. Sci. 2010, 17, 131-139. 
109. Dhanasekaran, P.; Gupta, N.M. Factors affecting the production of $\mathrm{H} 2$ by water splitting over a novel visible-light-driven photocatalyst $\mathrm{GaFeO}_{3}$. Int. J. Hydrog. Energy 2012, 37, 4897-4907.

110. Tang, P.; Chen, H.; Cao, F.; Pan, G. Magnetically recoverable and visible-light-driven nanocrystalline $\mathrm{YFeO}_{3}$ photocatalysts. Catal. Sci. Technol. 2011, 1, 1145-1148.

111. Yuan, Z.; Wang, Y.; Sun, Y.; Wang, J.; Bie, L.; Duan, Y. Sunlight-activated $\mathrm{AlFeO}_{3} / \mathrm{TiO}_{2}$ photocatalyst. Sci. China Ser. B 2006, 49, 67-74.

112. Takei, T.; Haramoto, R.; Dong, Q.; Kumada, N.; Yonesaki, Y.; Kinomura, N.; Mano, T.; Nishimoto, S.; Kameshima, Y.; Miyake, M. Photocatalytic activities of various pentavalent bismuthates under visible light irradiation. J. Solid State Chem. 2011, 184, 2017-2022.

113. Kako, T.; Zou, Z.; Katagiri, M.; Ye, J. Decomposition of Organic Compounds over $\mathrm{NaBiO}_{3}$ under Visible Light Irradiation. Chem. Mater. 2006, 19, 198-202.

114. Chang, X.; Yu, G.; Huang, J.; Li, Z.; Zhu, S.; Yu, P.; Cheng, C.; Deng, S.; Ji, G. Enhancement of photocatalytic activity over $\mathrm{NaBiO}_{3} / \mathrm{BiOCl}$ composite prepared by an in situ formation strategy. Catal. Today 2010, 153, 193-199.

115. Yu, X.; Zhou, J.; Wang, Z.; Cai, W. Preparation of visible light-responsive $\mathrm{AgBiO}_{3}$ bactericide and its control effect on the Microcystis aeruginosa. J. Photochem. Photobiol. 2010, 101, 265-270.

116. Sun, M.; Jiang, Y.; Li, F.; Xia, M.; Xue, B.; Liu, D. Dye degradation activity and stability of perovskite-type $\mathrm{LaCoO}_{3-\mathrm{x}}(\mathrm{x}=0 \sim 0.075)$. Mater. Trans. 2010, 51, 2208-2214.

117. Tang, P.; Sun, H.; Cao, F.; Yang, J.; Ni, S.; Chen, H. Visible-light driven $\mathrm{LaNiO}_{3}$ nanosized photocatalysts prepared by a sol-gel process. Adv. Mater. Res. 2011, 279, 83-87.

118. Li, J.; Zeng, J.; Jia, L.; Fang, W. Investigations on the effect of $\mathrm{Cu}^{2+} / \mathrm{Cu}^{1+}$ redox couples and oxygen vacancies on photocatalytic activity of treated $\mathrm{LaNi}_{1-\mathrm{x}} \mathrm{Cu}_{\mathrm{x}} \mathrm{O}_{3}(\mathrm{x}=0.1,0.4,0.5)$. Int. J. Hydrog. Energy 2010, 35, 12733-12740.

119. Singh, J.; Uma, S. Efficient Photocatalytic Degradation of Organic Compounds by Ilmenite $\mathrm{AgSbO}_{3}$ under Visible and UV Light Irradiation. J. Phys. Chem. C 2009, 113, 12483-12488.

120. Shi, J.; Ye, J.; Zhou, Z.; Li, M.; Guo, L. Hydrothermal Synthesis of $\mathrm{Na}_{0.5} \mathrm{La}_{0.5} \mathrm{TiO}_{3}-\mathrm{LaCrO}_{3}$ Solid-Solution Single-Crystal Nanocubes for Visible-Light-Driven Photocatalytic $\mathrm{H}_{2}$ Evolution. Chem. Eur. J. 2011, 17, 7858-7867.

121. Borse, P.H.; Cho, C.R.; Yu, S.M.; Yoon, J.H.; Hong, T.E.; Bae, J.S.; Jeong, E.D.; Kim, H.G. Improved photolysis of water from ti incorporated double perovskite $\mathrm{Sr}_{2} \mathrm{FeNbO}_{6}$ lattice. Bull. Korean Chem. Soc. 2012, 33, 3407-3412.

122. Borse, P.H.; Lim, K.T.; Yoon, J.H.; Bae, J.S.; Ha, M.G.; Chung, E.H.; Jeong, E.D.; Kim, H.G. Investigation of the physico-chemical properties of $\mathrm{Sr}_{2} \mathrm{FeNb}_{1-\mathrm{x}} \mathrm{W}_{\mathrm{x}} \mathrm{O}_{6}(0.0 \leq \mathrm{x} \leq 0.1)$ for visible-light photocatalytic water-splitting applications. J. Korean Phys. Soc. 2014, 64, 295-300.

123. Hu, R.; Li, C.; Wang, X.; Sun, Y.; Jia, H.; Su, H.; Zhang, Y. Photocatalytic activities of $\mathrm{LaFeO}_{3}$ and $\mathrm{La}_{2} \mathrm{FeTiO}_{6}$ in p-chlorophenol degradation under visible light. Catal. Commun. 2012, 29, 35-39.

124. Hatakeyama, T.; Takeda, S.; Ishikawa, F.; Ohmura, A.; Nakayama, A.; Yamada, Y.; Matsushita, A.; Yea, J. Photocatalytic activities of $\mathrm{Ba}_{2} \mathrm{RBiO}_{6}(\mathrm{R}=\mathrm{La}, \mathrm{Ce}, \mathrm{Nd}, \mathrm{Sm}, \mathrm{Eu}, \mathrm{Gd}, \mathrm{Dy})$ under visible light irradiation. J. Ceram. Soc. Jpn. 2010, 118, 91-95. 
125. Clark, J.H.; Dyer, M.S.; Palgrave, R.G.; Ireland, C.P.; Darwent, J.R.; Claridge, J.B.; Rosseinsky, M.J. Visible light photo-oxidation of model pollutants using $\mathrm{CaCu}_{3} \mathrm{Ti}_{4} \mathrm{O}_{12}$ : An experimental and theoretical study of optical properties, electronic structure, and selectivity. J. Am. Chem. Soc. 2011, 133, 1016-1032.

126. Iwakura, H.; Einaga, H.; Teraoka, Y. Photocatalytic Properties of Ordered Double Perovskite Oxides. J. Novel Carbon Resour. Sci. 2011, 3, 1-5.

127. Zhu, S.; Fu, H.; Zhang, S.; Zhang, L.; Zhu, Y. Two-step synthesis of a novel visible-light-driven $\mathrm{K}_{2} \mathrm{Ta}_{2} \mathrm{O}_{6-\mathrm{x}} \mathrm{N}_{\mathrm{x}}$ catalyst for the pollutant decomposition. J. Photochem. Photobiol. A 2008, 193, 33-41.

128. Kanhere, P.; Tang, Y.; Zheng, J.; Chen, Z. Synthesis, photophysical properties, and photocatalytic applications of $\mathrm{Bi}$ doped $\mathrm{NaTaO}_{3}$ and $\mathrm{Bi}$ doped $\mathrm{Na}_{2} \mathrm{Ta}_{2} \mathrm{O}_{6}$ nanoparticles. J. Phys. Chem. Solids 2013, 74, 1708-1713.

129. Hara, M.T.T.; Kondo, J.N.; Domen, K. Photocatalytic reduction of water by TaON under visible light irradiation. Catal. Today 2004, 90, 313-317.

130. Ishikawa, A.; Takata, T.; Kondo, J.N.; Hara, M.; Kobayashi, H.; Domen, K. Oxysulfide $\mathrm{Sm}_{2} \mathrm{Ti}_{2} \mathrm{~S}_{2} \mathrm{O}_{5}$ as a Stable Photocatalyst for Water Oxidation and Reduction under Visible Light Irradiation ( $\lambda \leq 650 \mathrm{~nm})$. J. Am. Chem. Soc. 2002, 124, 13547-13553.

131. Siritanaratkul, B.; Maeda, K.; Hisatomi, T.; Domen, K. Synthesis and Photocatalytic Activity of Perovskite Niobium Oxynitrides with Wide Visible-Light Absorption Bands. ChemSusChem 2011, 4, 74-78.

132. Maeda, K.; Higashi, M.; Siritanaratkul, B.; Abe, R.; Domen, K. $\mathrm{SrNbO}_{2} \mathrm{~N}$ as a Water-Splitting Photoanode with a Wide Visible-Light Absorption Band. J. Am. Chem. Soc. 2011, 133, 12334-12337.

133. Higashi, M.; Abe, R.; Takata, T.; Domen, K. Photocatalytic Overall Water Splitting under Visible Light Using $\mathrm{ATaO}_{2} \mathrm{~N}(\mathrm{~A}=\mathrm{Ca}, \mathrm{Sr}, \mathrm{Ba})$ and $\mathrm{WO}_{3}$ in a $\mathrm{IO}_{3}{ }^{-} / \mathrm{I}^{-}$Shuttle Redox Mediated System. Chem. Mater. 2009, 21, 1543-1549.

134. Maeda, K.; Domen, K. Preparation of $\mathrm{BaZrO}_{3}-\mathrm{BaTaO}_{2} \mathrm{~N}$ solid solutions and the photocatalytic activities for water reduction and oxidation under visible light. J. Catal. 2014, 310, 67-74.

135. Le Paven-Thivet, C.; Ishikawa, A.; Ziani, A.; Le Gendre, L.; Yoshida, M.; Kubota, J.; Tessier, F.; Domen, K. Photoelectrochemical Properties of Crystalline Perovskite Lanthanum Titanium Oxynitride Films under Visible Light. J. Phys. Chem. C 2009, 113, 6156-6162.

136. Kako, T.; Kikugawa, N.; Ye, J. Photocatalytic activities of $\mathrm{AgSbO}_{3}$ under visible light irradiation. Catal. Today 2008, 131, 197-202.

(C) 2014 by the authors; licensee MDPI, Basel, Switzerland. This article is an open access article distributed under the terms and conditions of the Creative Commons Attribution license (http://creativecommons.org/licenses/by/4.0/). 